\title{
SURFACTANT SCREENING OF DIESEL-CONTAMINATED SOIL
}

\author{
Robert $W$. Peters, ${ }^{\dagger}$ Carlo D. Montemagno, $\$$ and Linda Shem ${ }^{\dagger}$ \\ Energy Systems Division ${ }^{\dagger}$ \\ Environmental Assessment and Information Sciences Division ${ }^{5}$ \\ Argonne National Laboratory \\ 9700 South Cass Avenue \\ Argonne, IL 60439
}

and

Barbara-Ann Lewis

Department of Civil Engineering

The Technological Institute

Northwestern University

Evanston, IL 60208

\begin{abstract}
At one installation, approximately 60,000 gal of No. 2 diesel fuel leaked into the subsurface environment, with contamination at depths of 6 to $34 \mathrm{~m}$ below the surface. Argonne National Laboratory was contracted to perform treatability studies for site remediation. The treatability studies focused on four separate phases: (1) leachability studies on the various contaminated soil borings, (2) air stripping studies, (3) bioremediation studies, and (4) surfactant screening/surfactant flooding studies.

This paper summarizes the fourth phase of the research program in which twenty-one surfactants were screened for possible use to mobilize the organics from the contami-
\end{abstract}

"Correspondence should be directed to this author. References in this paper to commercial products do not constitute or imply endorsement of these products by the authors or the Laboratory. The viewpoints expressed here are not necessarily those of the Laboratory or its sponsors. 
nated soil prior to bioremediation. Anionic surfactants resulted in the greatest degree of diesel mobilization. The most promising surfactants will be employed on actual contaminated soil samples obtained from the site.

\section{INTRODUCTION}

Remediation of soil contaminated with liquid fuels, oils, and organic solvents is a problem requiring immediate and economical solutions. One solution involves the use of surfactants. Selection of the most appropriate compound(s) and evaluation of the potential for successful remediation at a particular site depends on an understanding of the physicochemical interactions among the surfactants, the contaminants, the soil, water, and the leaching solution. This paper provides some technical background for surfactant use and describes application of a surfactant selection and screening process to a site in California contaminated with No. 2 diesel fuel to a depth of about $35 \mathrm{~m}$.

\section{Site History}

The soil used in this study was obtained from a site contaminated with No. 2 diesel fuel. An accidental puncture of a fuel line resulted in the release of approximately 60,000 gal into the ground. Contamination has spread to depths of $32 \mathrm{~m}$, making conventional on-site treatment difficult. As part of an overall treatability study, air stripping, leaching, bioremediation, and surfactant flooding are being investigated as potential remediation alternatives. As a preliminary to bench-scale surfactant flooding of undisturbed soil columrs, a number of surfactants were screened in a batch shaker test to examine their performance in mobilizing the organics from the contaminated soil.

\section{BACKGROUND}

\section{Surfactants}

"Surfactant" (surface active agent) is descriptive of the compound's fundamental properties, including an amphipatic structure, monolayer orientation at interfaces, and adsorption at interfaces [6]. A molecule containing an amphipathic structure consists of groups with opposing solubility tendencies, one group being lipophilic (or fat soluble), the other hydrophilic (water soluble). In a two-phase solution, the groups will align between the phases as their opposing groups are adsorbed into the different layers. If the ratio of hydrophilic/lipophilic groups (the hydrophilic-lipophilic balance, HLB) is low, the surfactant is more 
oil soluble and would enhance the oil solubility of water soluble substances. If the HLB ratio is high, the opposite occurs [11].

High-HLB surfactants have found their usefulness in commercial and industrial products such as soaps, detergents, emulsifiers, and dispersants. The nature of performance depends on the extent of branching and length of the lipophilic group and the charge of-the hydropilific group. Classification of surfactants is based on overall electrostatic charge (cationic, anionic, nonionic, or amphipathic).

\section{Mechanism and Use in Oil Industry}

The oil industry uses surfactants to enhance the recovery of crude oil from wells. The primary stage occurs by initial field pressure. When a saturated field is trapped, the oil present in the larger pore spaces will be forced to move with pressure gradient to the well. As oil vacates the reservoir, the pressure gradient drops and recovery slows. About 10 to $20 \%$ of the oil is recoverable in this stage. To increase this pressure gradient, water or steam is added to the reservoir, forcing the oil to the well. This method increases the recovery of oil by 20 to $40 \%$. The remaining 40 to $80 \%$ of the oil, which requires greater forces to extract, is held up in the smaller pores of the rock or soil by canillary forces and viscous forces (see Figure 1). This relatively immobile oil phase is referred to as the "residual oil," and the soil is at "residual saturation" in relation to the oil [16].

Oh and Slattery [13] discuss a critical value, known as the capillary number, in which residual saturation is reached and oil recovery is no longer practical. The capillary number, which is dimensionless, is defined as $\mathrm{Nc}=\mu \phi q / \gamma$, where:

$\mu=$ fluid viscosity,

$\phi=$ porosity of the soij. or rock,

$q=$ cross sectional flow rate of the water, and

$\gamma=$ interfacial tension between the oil and water.

This re'ation suggests that in order to enhance oil recovery (and therefore increase the capillary number), an increase in water viscosity or flow rate or a decrease in the interfacial tension would be required [5].

This is the idea behind the tertiary stage in oil production. Using a brine solution or surfactant to flood the reservoir has been shown to enhance recnvery by decreasing the interfacial tension between oil and water. It is possible to change the interfacial tension from a value of 20 to $30 \mathrm{dyn} / \mathrm{cm}$ for oil/water under normal conditions to as low as $10^{-3}$ or $10^{-4} \mathrm{dyn} / \mathrm{cm}$ with an appropriate surfactant [5].

A low interfacial tension requires optimum electrolyte concentration and salinity of the solution and alkyl chain length of 


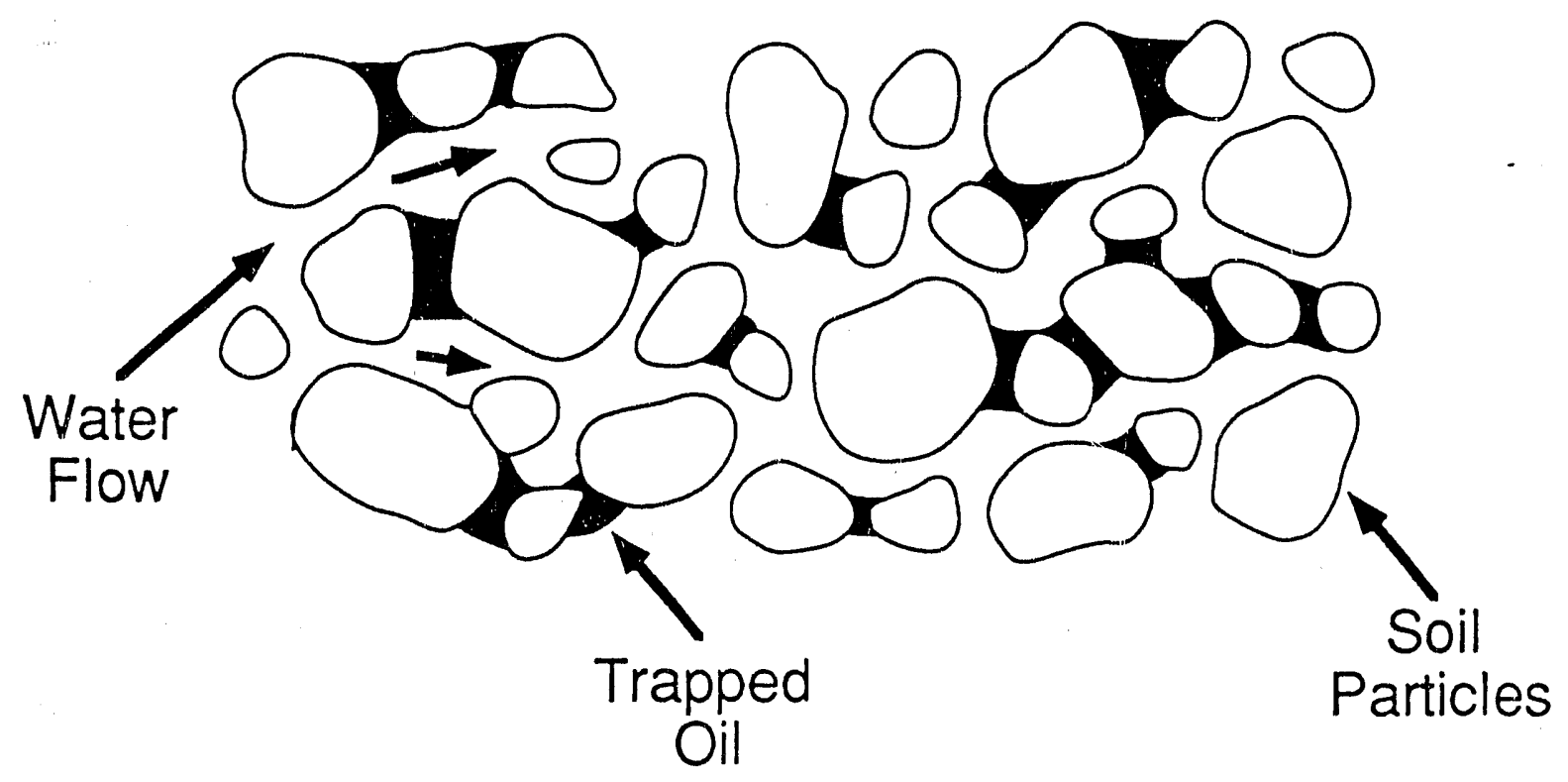

Eigure 1. SCHEMATIC DIAGRAM SHOWING RESIDUAL OIL WITHIN SOIL MATRIX [ADAPTED EROM REF. 16]

the surfactant. The ultra-low interfacial tension occurs at the concentration where the partition coefficient equals 1.0 and most of the surfactant is found at the interface. This point is called the critical micelle concentration (CMC). The CMC can be defined as the concentration of a micelle at which the rate of increase of electrical conductance with an increase in concentration levels off or proceeds at a much slower rate. Above and below the CMC, aggregates or micelles of the surfactant form in one of the phases present decreasing the surfactant's efficiency (see Figure 2). The CMC is dependent on factors such as surface concentration, structure of the oil phase, time, and temperature, and therefore is specific to the field situation [5].

The charge of the hydrophilic group is important in oil recovery. Generally, soils tend to have an overall negative charge, counterbalanced by exchangeable cations. Anionic surfactants provide the surface of oil droplets with a negative charge, resulting in repulsion by the soil (see Figure 3 ). This allows for increased mobility of the oil [5].

The wettability of the rock or soil also plays a role in the recovery of oil. An oil-wettable surface results in oil adsorbing to the surface of the soil, whereas a water-wettable surface leads to easier mobilization of the oil (see Figure 4). An increase in the ionia strength of a solution (by the addition of salts, acids, 

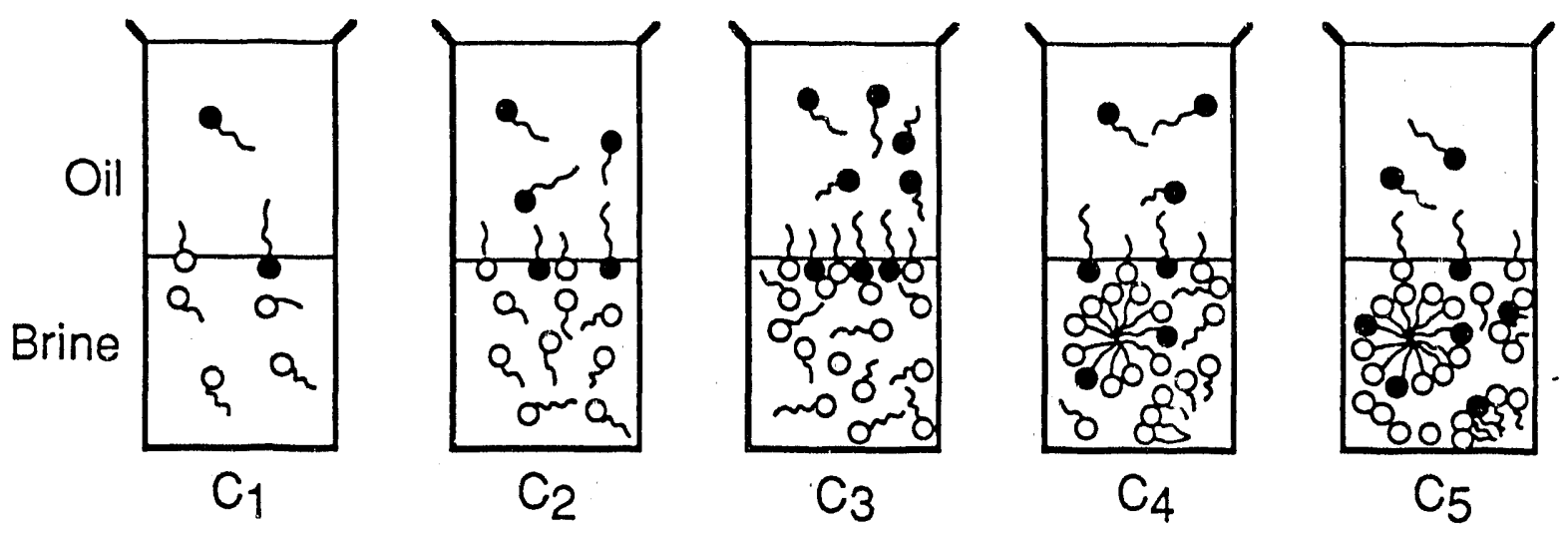

Increase in Surfactant Concentration
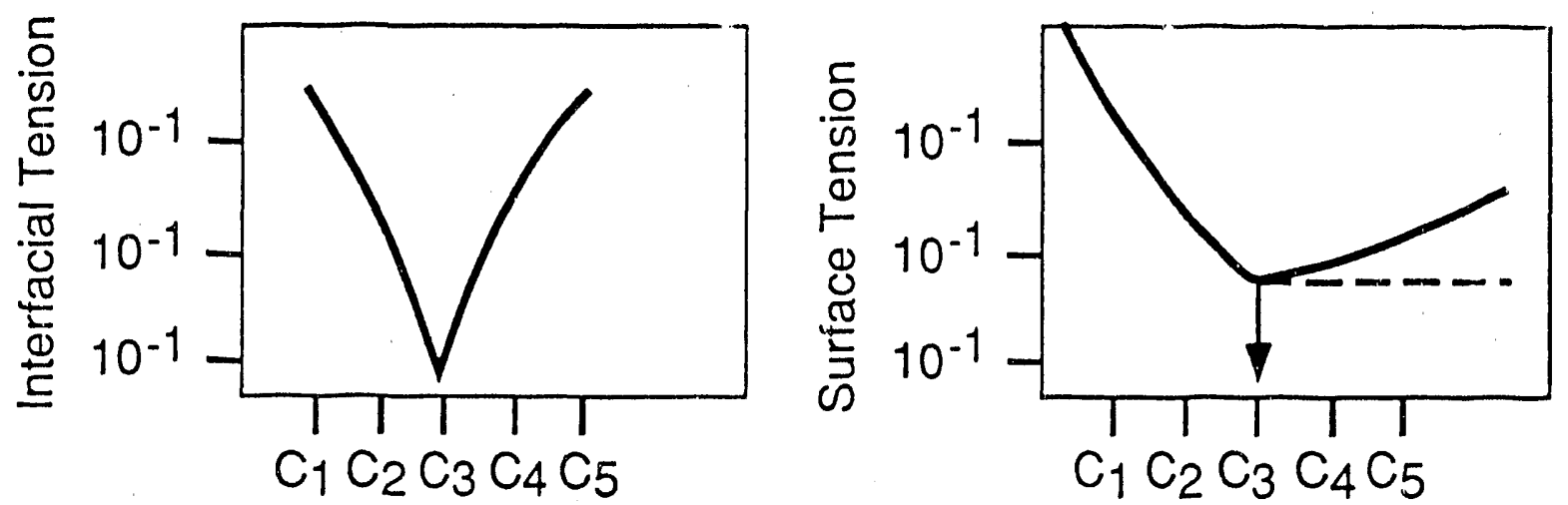

Figure 2. MICELLE FORMATION FOR VARIOUS SURFACTANT CONCENTRATIONS [ADAPTED FROM REE. 5]

or bases) will increase the water-wettability of the soil and better oil recovery. Sodium sulfonate surfactants are popular in oil recovery for their role in increasing water-wettability [5].

\section{Potential Use in Soil Remediation}

Through the mechanisms mentioned above (decreasing interfacial tension, increasing interfacial charge, and increasing the waterwettability of the soil), surfactants have found their usefulness in the oil production industry. However, the utility of surfactants in oil spill cleanup is a relatively recent idea. More widely known is the use of dispersants in surface water restoration [4, 11]. The use in soil remediation is primarily in the experimental stages. Soil washing [17] (soil scrubbing) is a technique in which soil is excavated and subjected to separation processes. Rickabaugh et al. [14] performed batch shaker and bench-scale tests on contaminated soil. They tested 14 different surfactants on soil contaminated with chlorinated hydrocarbons. Relying on research from tertiary oil recovery, they chose to use a blend of nonionic-anionic and nonionic-cationic as well as 


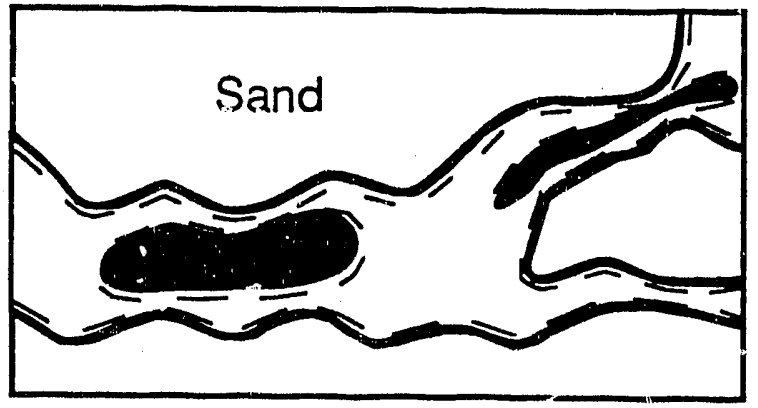

\section{High Surface Charge Density}

- Low interfacial tension

- Low interfacial viscosity

- High electrical repulsion between oil droplets and soil

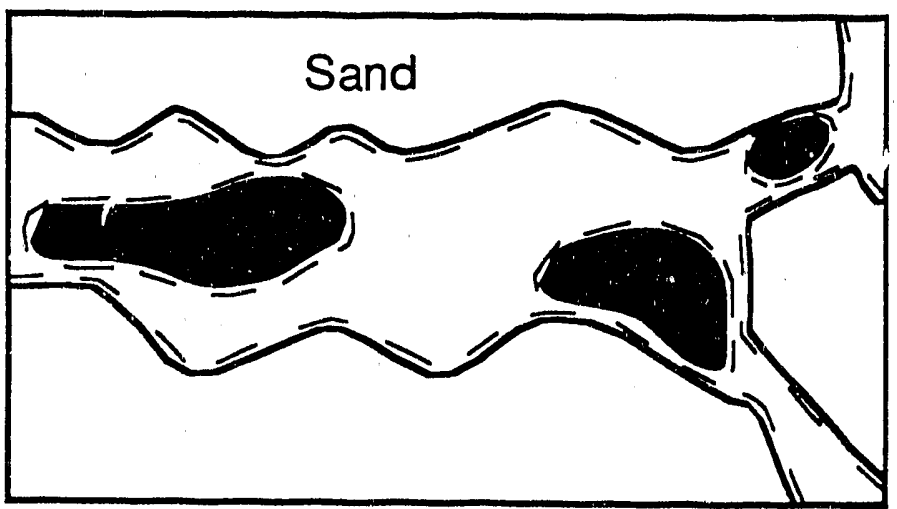

\section{Low Surface Charge Density}

- High interfacial tension

- High interfacial viscosity

- Low electrical repulsion between oil droplets and soil

Eigure 3. CHARGE DENSITY RELATIONSHIP FOR OIL-SOIL SYSTEM [ADAPTED EROM REE. 5]

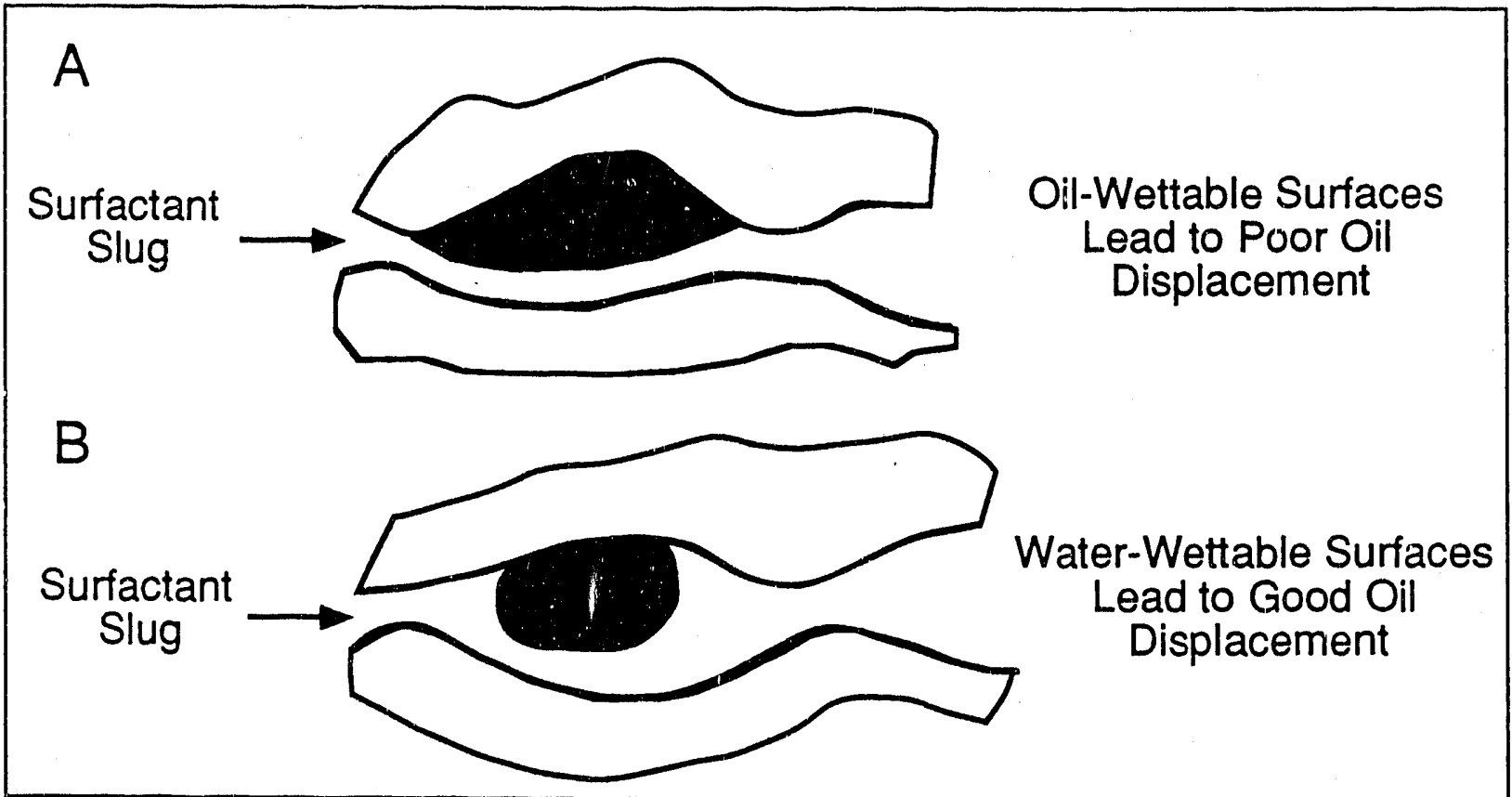

Figure 4. WETTABILITY, CONTACT ANGLE, AND OIL DISPLACEMENT RELATIONSHIP [ADAPTED FROM REE. 5] 
anionic and nonionic surfactants alone in their study. In the batch shaker tests, they mixed $10 \mathrm{~g}$ of soil with $200 \mathrm{~mL}$ of $0.5 \frac{5}{\circ}$, $1.0 \%$, and $2.0 \%$ surfactant solution, which was shaken for 2 to $4 \mathrm{~h}$. The surfactant solution was filtered, subjected to liquid-liquid extraction, and analyzed by gas chromatography. Results showed that the $2 \%$ solutions removed the greatest amount of contaminant and the $0.5 \%$ solutions removed the least amount of contaminant. Blends of surfactants also gave slightly better removal results than using anionic or nonionic surfactants alone. Rickabaugh et al. further analyzed a $2 \%$ solution of five surfactants and blends of five surfactants through soil column leaching. Again, results showed the blends to be more effective in removing the hydrocarbons. Removals in the columns were $115 \mathrm{mg} / \mathrm{kg}$ for the blend, and $97.5,92.4$, and $69.5 \mathrm{mg} / \mathrm{kg}$ for the nonionic, anionic, and cationic surfactants, respectively.

Allen et al. [2] performed similar batch bench-scale tests with phenol and $0^{-}, \mathrm{m}-$, and $\mathrm{p}$-cresol contaminated soils. They compared removal efficiencies of plain water, a heated alkaline solution, and a surfactant solution. The alkaline solutions were observed to perform best, followed closely by plain water. The surfactant solution resulted in the lowest removal efficiencies. Rickabaugh et al. [14] considered but did not use a solution of higher $\mathrm{pH}$ because they felt that a high $\mathrm{pH}$ would result in increased loss of the surfactant to the environment through soil adsorption.

In-situ soil flooding, using the same concept as tertiary oil recovery, is even more novel as a remediation technique than is soil washing. A few pilot studies have been performed, but it is too early for conclusive evidence on the success and practicality of this alternative. Nash [10] performed in-situ soil flooding of soils contaminated with hydrocarbons and chlorinated hydrocarbons. After determining the success of various surfactants in laboratory screening and soil column tests similar to Rickabaugh et al., Nash applied natural and synthetic surfactant solutions to 10 holes dug 1-ft deep into the ground of a contaminated site. The application was at 3 in. of infiltration/day for 4 to 6 days. Treated.soil samples were taken from various depths below the holes for analysis in the laboratory. Results showed no measurable contaminant removal, and some of the samples even showed an increase in contaminant concentrations. The low removal was most likely due to surfactant dilution by heavy rains that occurred 3 days during the application period. Possibly, contact of the surfactant with much of the soil decreased as the rain saturated the soil and flowed through the larger, more conductive pores of the soil matrix [7]. The increase in the contaminant concentration of some of the treated samples is most likely due to variation in the real site situation; moreover, the initial values used were not representative of all points in the site.

In-situ soil flooding has a very long way to go before it will be a viable technological remediation alternative. Along with the problems that Nash encountered, other difficulties that need further study include the following: 
1. surfactant solutions after elutriation may require further treatment,

2. the potential of the contaminant spreading further, and

3. recovery of the surfactant from the eluate.

One concern about surfactant flooding as a remediation technique is the possibility that the environment may become contaminated by the surfactant itself. McGill [9] does not recommend the use of water soluble products in soil remediation, perhaps because of adverse effects on crop production. However, much research is being performed on the biodegradability of surfactants $[1,12]$. Cyanamid has performed BOD and COD studies and aquatic toxicity tests on their products. Results of such tests performed on Cyanamer $P-70$ (used in this project) yielded COD values of $405 \mathrm{~g}$ $\mathrm{O}_{2} / \mathrm{kg}$ and $\mathrm{BOD}_{5}$ of $9 \mathrm{~g} \mathrm{O} / \mathrm{kg}$. Standard toxicity tests on this product showed no toxic effects on bluegills and rainbow trout [8]. The potential biodegradability of surfactants may prove to be more important to the application of surfactant flooding in combination with biotreatment. Oils mobilized and pumped from the subsurface by surfactant solutions may be biotreated on-site.

\section{METHODS}

\section{Soil Sampling}

As part of an overall treatability study of the contaminated site mentioned above, air stripping, leaching, bioremediation, and surfactant flooding are under investigation using laboratory and bench-scaie experiments. The studies described in this paper are part of a surfactant screening process, which is preliminary to the surfactant flooding of undisturbed soil columns of nominal $19 \mathrm{~cm}$ in diameter and $19 \mathrm{~cm}$ in length taken from the site. Core barrel samples were collected in nominal $18 \mathrm{-cm}$ diameter core barrels at depths ranging from 6 to $32 \mathrm{~m}$ below the surface of the soil.

Samples were collected from one soil boring reaching $32 \mathrm{~m}$ below the surface of the soil. This boring was cut into $38-\mathrm{cm}$ segments. The relatively undisturbed soil columns were shipped to Argonne National Laboratory and the University of. Notre Dame for bench-scale analyses. Soi i from a column depth of $18.3 \mathrm{~m}$ below the surface of the soil was used to test the peiformance of 21 commercial surfactants (see Table 1). Six anionic surfactants, eleven nonionic surfactants, three cationic surfactants, and one undetermined surfactant were tested using a $2 \%$ solution at their natural pH and room temperature. No blends of surfactants were considered. These surfactants were chosen for their present uses as dispersants and emulsifiers of oils and for their potential biodegradability properties. 
Table 1. SURFACTANTS USED IN SCREENING STUDY

\begin{tabular}{llll}
\hline Surfactant & $\begin{array}{c}\text { Surfactant } \\
\text { No. }\end{array}$ & Manufacturer & Use \\
\hline
\end{tabular}

Anionic:

$\begin{array}{lcll}\text { Cyanamer P-35(I) } & 15 & \text { American Cyanamide Co. } & \text { Dispersant } \\ \text { Cyanamer P-35(s) } & 16 & \text { American Cyanamide Co. } & \text { Dispersant } \\ \text { Cyanamer P-70(I) } & 17 & \text { American Cyanamide Co. } & \text { Dispersant } \\ \begin{array}{l}\text { Poly Sodium Vinyl } \\ \text { Sulfonate }\end{array} & 18 & \text { Air Products \& Chemicals } & \text { Dispersant } \\ \begin{array}{l}\text { Witcolate } 6462 \\ \text { Witcolate } 6465\end{array} & 4 & \text { Witco Corporation } & \text { Emulsifier } \\ & 5 & \text { Witco Corporation } & \text { Emulsifier }\end{array}$

Nonionic:

$\begin{array}{lrll}\text { Activ } 8000 & 19 & \text { Bullen Midwest Company } & \text { Emulsifier } \\ \text { Activ } 8000 \text { TDA } & 20 & \text { Bullen Midwest Company } & \text { Emulsifier } \\ \text { Activ } 8000 \text { CEM } & 21 & \text { Bullen Midwest Company } & \text { Emulsifier } \\ \text { Surfynol } 468 & 14 & \text { Air Products \& Chemicals } & \text { Emulsifier } \\ \text { Surfynol } 485 & 13 & \text { Air Products \& Chemicals } & \text { Emulsifier } \\ \text { Witconol } 2648 & 6 & \text { Witco Corporation } & \text { Defoam/Emul. } \\ \text { Witconol } 2665 & 7 & \text { Witco Corporation } & \text { Defoam/Emul. } \\ \text { Witconol } 4143 & 8 & \text { Witco Corporation } & \text { Defoam/Emul. } \\ \text { Witconol } 2642 & 9 & \text { Witco Corporation } & \text { Defoam/Emul. } \\ \text { Witconol } 2640 & 10 & \text { Witco Corporation } & \text { Emulsifier } \\ \text { Witconol } 5909 & 11 & \text { Witco Corporation } & \text { Dispersant } \\ & & & \end{array}$

\section{Cationic:}

$\begin{array}{lrll}\text { Emcol CC-42 } & 1 & \text { Witco Corporation } & \text { Dispersant } \\ \text { Emcol CC-26 } & 12 & \text { Witco Corporation } & \text { Dispersant } \\ \text { Witcamine 6642 } & 3 & \text { Witco Corporation } & \text { Dispersant/ } \\ & & & \text { Emulsifier }\end{array}$

\section{Unknown:}

Toxigon 2000

2 Formula IV Corporation

\section{DISCLAIMER}

\footnotetext{
This report was prepared as an account of work sponsored by an agency of the United States Government. Neither the United States Gnvernment nor any agency thereof, nor any of their employees, makes any warranty, express or implied, or assumes any legal liability or responsibility for the accuracy, completeness, or usefulness of any information, apparatus, product, or process disclosed, or represents that its use would not infringe privately o,wned rights. Reference herein to any specific commercial product, process, or service by trade name, trademark, manufacturer, or otherwise does not necessarily constitute or imply its endorsement, recommendation, or favoring by the United States Government or any agency thereof. The views and opinions of authors expressed herein do not necessarily state $c^{6}$ reflect those of the United States Government or any agency thereof.
} 
Soil taken from the chosen column was characterized and analyzed for its porosity, moisture content, soil pH, particle size distribution, and cation exchange capacity. This particular soil depth was chosen due to its high total petroleum hydrocarbon (TPH) concentration. The soil sections were also subjected to total petroleum hydrocarbon analyses (measured by gas chromatographic techniques), after treatment with carbon disulfide to extract-the organic contaminants (see section described below).

For the surfactant screening studies, the soil samples were air-dried, ground with a ceramic mortar and pestle to pass a 2-mm sieve (U.S. Sieve Size No. 10) to ensure uniformity of the contaminant and greater exposure of soil particle surface area. This procedure may have resulted in the volatilization of some organic compounds. These subsamples were subjected to the procedures described below.

\section{Soil Extraction for Total Petroleum Hydrocarbons (TPH)}

The method used for TPH measurements was adapted from California's "Leaking Underiround Fuel Tank Field Manual" [15] and EPA's "Evaluation of Soils from In-sjicu Treatment" [18]. To determine the initial TPH concentration of the soil, $1.0 \mathrm{~g}$ (wet weight) of soil was mixed with $10 \mathrm{~mL}$ of water to form a soil slurry. This slurry was subjected to extraction with $10 \mathrm{~mL}$ of carbon disulfide $\left(\mathrm{CS}_{2}\right)$, shaken for 5 to $10 \mathrm{~min}$ and centrifuged for $10 \mathrm{~min}$ at $3000 \mathrm{rpm}$. An aliquot (between 2.5 and $4.0 \mathrm{~mL}$ ) of the extract was passed through a syringe (containing anhydrous sodium sulfate to remove extraneous water) and a $0.45-\mu \mathrm{m}$ syringe filter (to separate out any fines) into a $4-\mathrm{mL}$ vial, capped, and stored in a refrigerator until analysis by gas chromatography techniques. In accordance with our quality assurance/quality control (QA/QC) protocol for this project, the initial TPH measurements were performed in triplicate to obtain more accurate, consistent results. Moisture content of the soil was performed by gravimetric analysis and oven dry weights $\left(110^{\circ} \mathrm{C}\right)$ of the soil were used in calculations of the results. TPH is repre-sented as $\mathrm{mg} T P H / \mathrm{kg}$ of soil. Sample calculations are presented in Appendix I.

\section{Soil Extraction for Surfactant Screening}

Samples were prepared (for a total of 44 samples) in the following combinations:

- $10 \mathrm{~g}$ soil + $50 \mathrm{~mL} 2 \%$ surfactant solution (21 samples),

- $50 \mathrm{~mL} 2 \%$ surfactant solution alone $(21$ controls of surfactant without soil), and

- $10 \mathrm{~g}$ soil + $50 \mathrm{~mL}$ water (2 controls on the soil reaction with water without surfactant). 
These samples were prepared in 100-mL plastic cups with lids, shaken on an Ebenbach shaker table for $1.0 \mathrm{~h}$, and left to settle for several hours. Solutions and soils were separated by gravity filtration, using paper funnel filters, to be analyzed separately. Figure 5 shows the experimental set-up for these experiments.

In 50-mL centrifuge tubes, the filtrates were subjected to liquid-liquid extraction with carbon disulfide at approximately 0.125 part $C_{2}$ to 1.0 part solution $\left(C S_{2}\right.$ ranged between 0.09 and 0.3 part to 1.0 part solution). The two liquid-phase solutions were shaken by wrist action for 5 to $10 \mathrm{~min}$ and allowed to separate (or centrifuged for $10 \mathrm{~min}$ at $3000 \mathrm{rpm}$ if separation proved difficult). An aliquot of 2.5 to $4.0 \mathrm{~mL}$ of the $\mathrm{CS}_{2}$ phase was then pipetted from the centrifuge tubes and subjected to the same dehydration and filtering process as for the TPH analyses. The controls of the surfactant solution alone were also subjected to the same liquidliquid extraction.

The remaining treated soil from each surfactant treatment was subjected to a posttreatment TPH analysis using the same procedures as described above for the initial TPH. Approximately 1.5 to $1.9 \mathrm{~g}$ of samples from the original $10 \mathrm{~g}$ was used for this TPH analysis. Again, dry weights were determined for calculations using a separate portion of the treated soil for calculations.

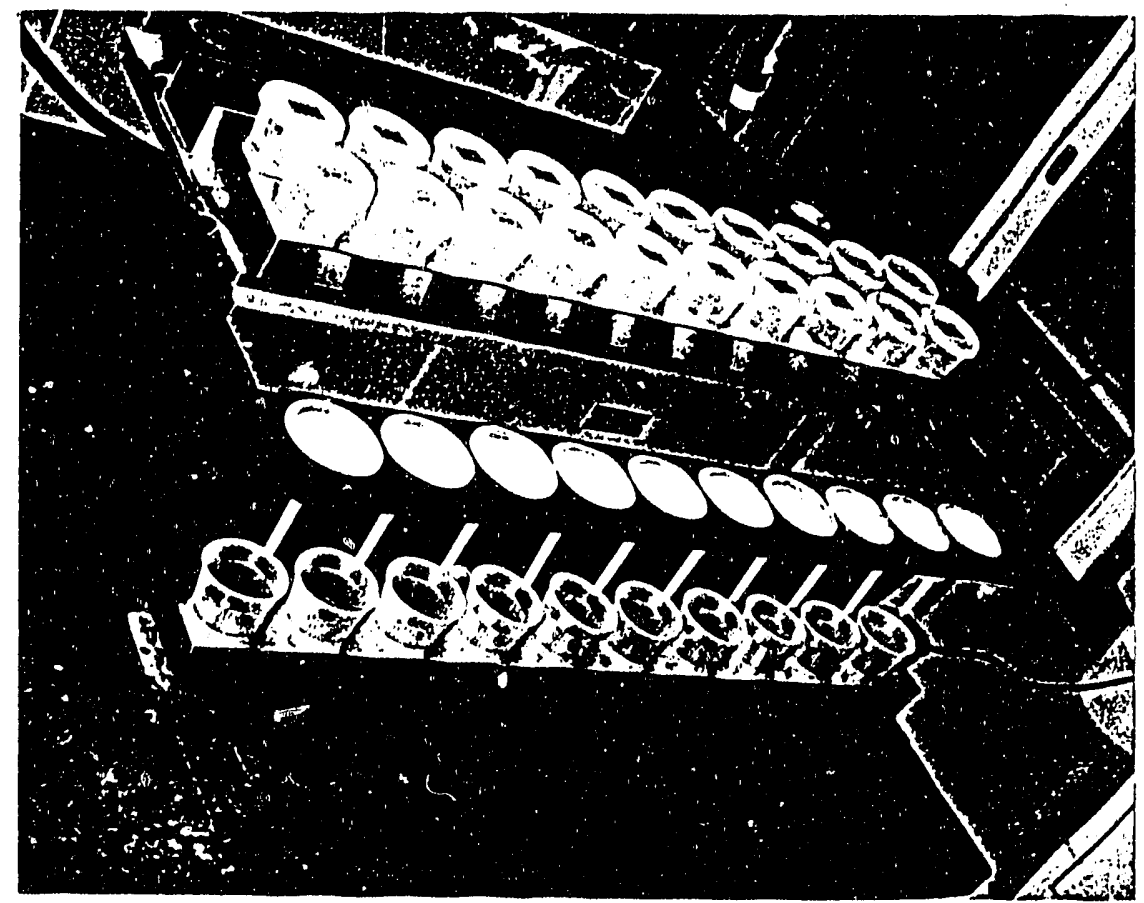

Figure 5. SETUP FOR THE SURFACTANT SCREENING EXPERIMENTS 


\section{Gas Chromatography Analysis of Extracts}

The carbon disulfide extracts obtained from the soil batch extractions were analyzed by gas chromatography, initially with a Varian 3700 gas chromatograph (GC) using a supelco packed column (Petrocol B), equipped with a flame ionization detector (FID), generally following specifications described in the California LUET manual [15] and approved for ASTM Method D2887 [3]. The gas chromatograph runs were programmed to operate at an initial temperature of $40^{\circ} \mathrm{C}$; this temperature was increased by $10^{\circ} \mathrm{C} / \mathrm{min}$ increments to a final temperature of 245 to $345^{\circ} \mathrm{C}$. Samples treated with surfactants coded 1 to 13 and 18 were analyzed using this GC. Subsequently, a Hewlett-Packard (HP) Model 5880A gas chromatograph was used, which was equipped with an FID and a split injection, using a J\&W Scientific capillary column containing a DB5 phase and a film thickness of $0.25 \mu \mathrm{m}$. The gas chromatograph runs were programmed to operate at an initial temperature of $40^{\circ} \mathrm{C}$, which was increased by $4^{\circ} \mathrm{C} / \mathrm{min}$ increments to a final temperature of 224 to $310^{\circ} \mathrm{C}$ that was maintained for 5 to $10 \mathrm{~min}$. Surfactants coded 14 to 17 and 19 to 21 were analyzed using this GC. Appendix. II describes the gas chromatography standards, precision and accuracy of the methods, and difficulties with these procedures.

\section{GOALS AND OBJECTIVES OF THIS STUDY}

The goals and objectives for the surfactant studies include:

1. Investigation for the mobilization of organics from the contaminated soil using various surfactants employing a screening procedure.

2. Investigation of the impacts of biodegradable surfactants on microbial activity utilizing a screening procedure.

3. Subsequent testing in in-situ reactors of the biodegradable surfactants showing favorable results from the screening process.

This paper presents the results for the first project goal, employing a surfactant screening technique.

\section{RESULTS AND DISCISSION}

The mobilization of diesel fuel components was evaluated using 21 different surfactants ( 6 anionic, 11 nonionic, 3 cationic, and 1 unknown in terms of ionic nature). The surfactant concentrations employed in this study were all $2.0 \%$ by volume, each at its natiral $\mathrm{pH}$ and room temperature. The results of these screenings are 
presented both in terms of the removal of total petroleum hydrocarbons (TPH) and selected alkanes (C12 to C19).

\section{TPE Remova:}

Figures 6 and 7 summarize the TPH concentrations resulting after surfactant treatment (using 28 surfactant concentrations) remaining on the soil and mobilized into the surfactant eluate, respectively. Figure 8 (percentage removal of TEH from the soil, based upon mass balance principles) and Figure 9 (percent enhancement for removal of TPH over that of water alonel indicate that the percent removal of TPH from soil generally exceeded $60 \%$. High THH concentrations ( $500 \mathrm{mg} / \mathrm{kg}$ soil) in the eluate were achieved using surfactants Nos. 1, 2, 4, 8, 12, 13, 17, and 21. Very high residual TFH concentrations remained on the soil using surfactants Nos. 6 and 19 though 21, whereas low TPH concentrations were achieved using surfactants Nos. 3 through 5 and 13 through 18. TPH removal from the soil was enhanced using surfactants Nos. 3 through 5 and 13 through 16. A comparison of this enhancement with the surfactants listed in Table 1 indicates that the anioric surfactants generally provided the best removal of TPH from the diesel-contaminated soil used in this study.

\section{Alkane (C12 to (19) Removal}

For those surfactants showing an enhancement in the removal of TPH compounds over that of water alone, those compounds were analyzed using the Hewlett-Packard gas chromatograph as described

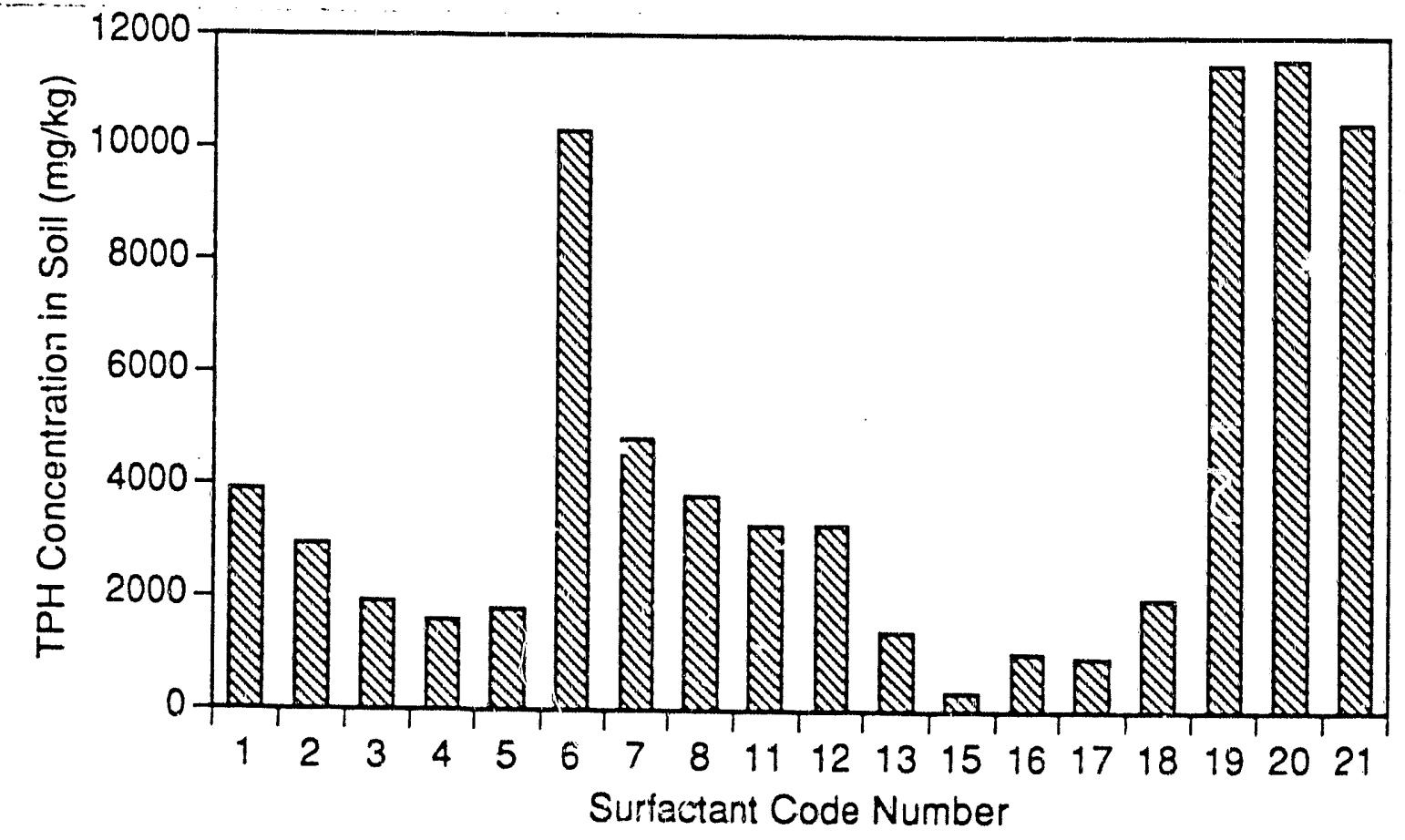

EIQUIE 6. TPH CONCENTRATTON TN THE SOII. AFTER SIREACTANT TREATMENT 


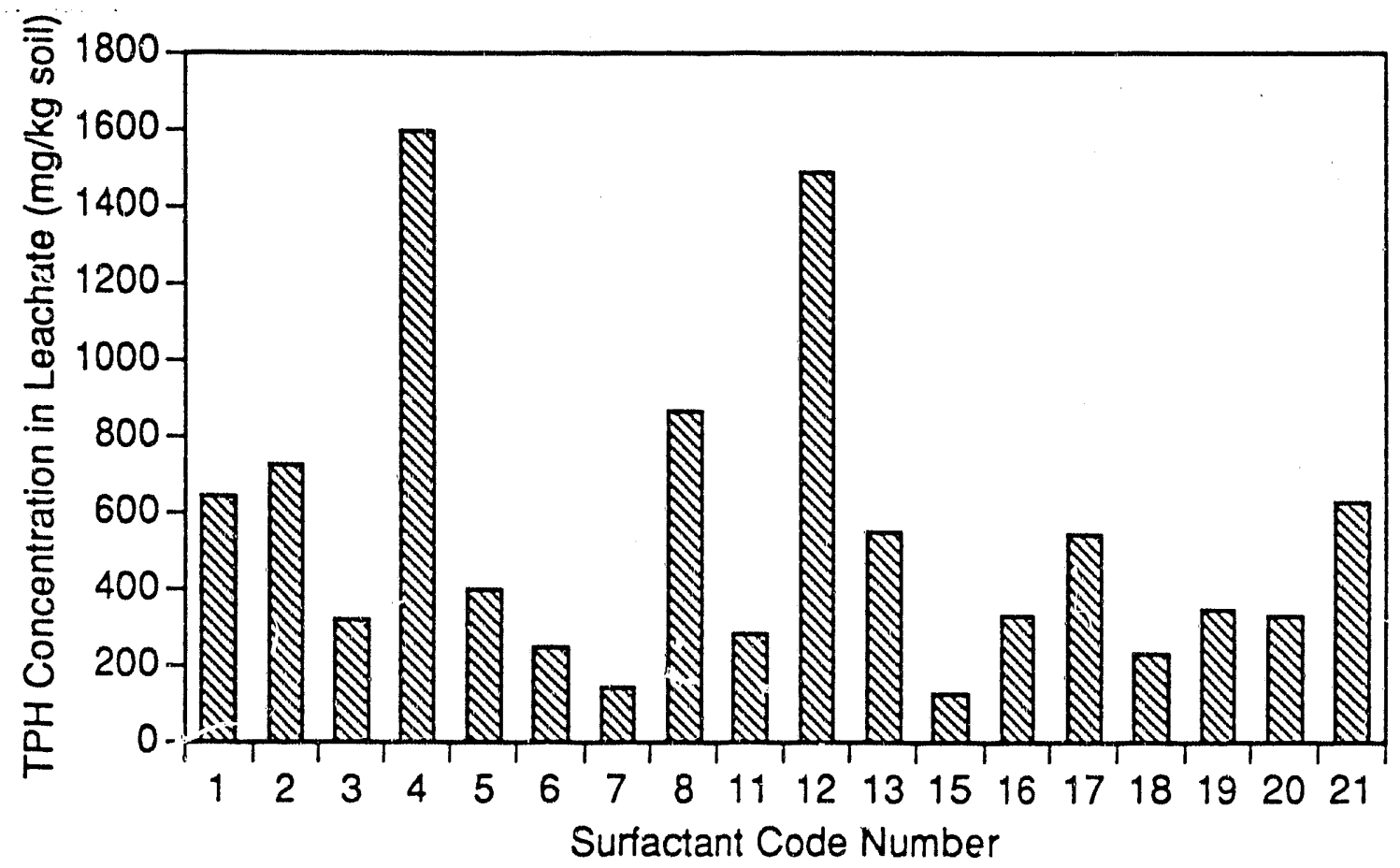

Figure 7. TPH CONCENTRATION IN THE SUREACTANT EILTRATE (BASED UPON THE SOIL WEIGHT)

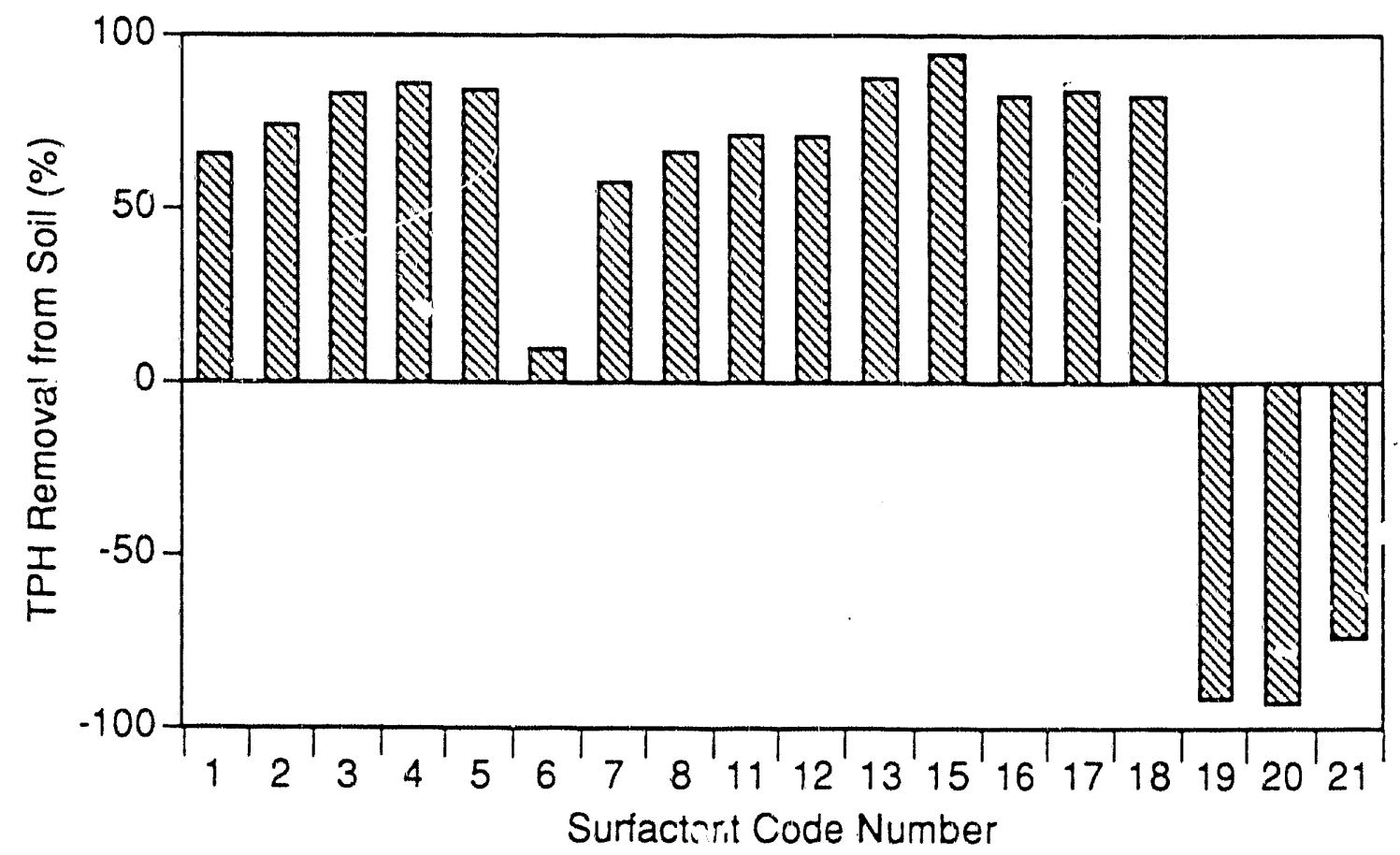

Eigure 8. PERCENT TPH REMOVAL EROM SOIL USING SURFACTANTS TO MOBIIIZE THE ORGANICS 


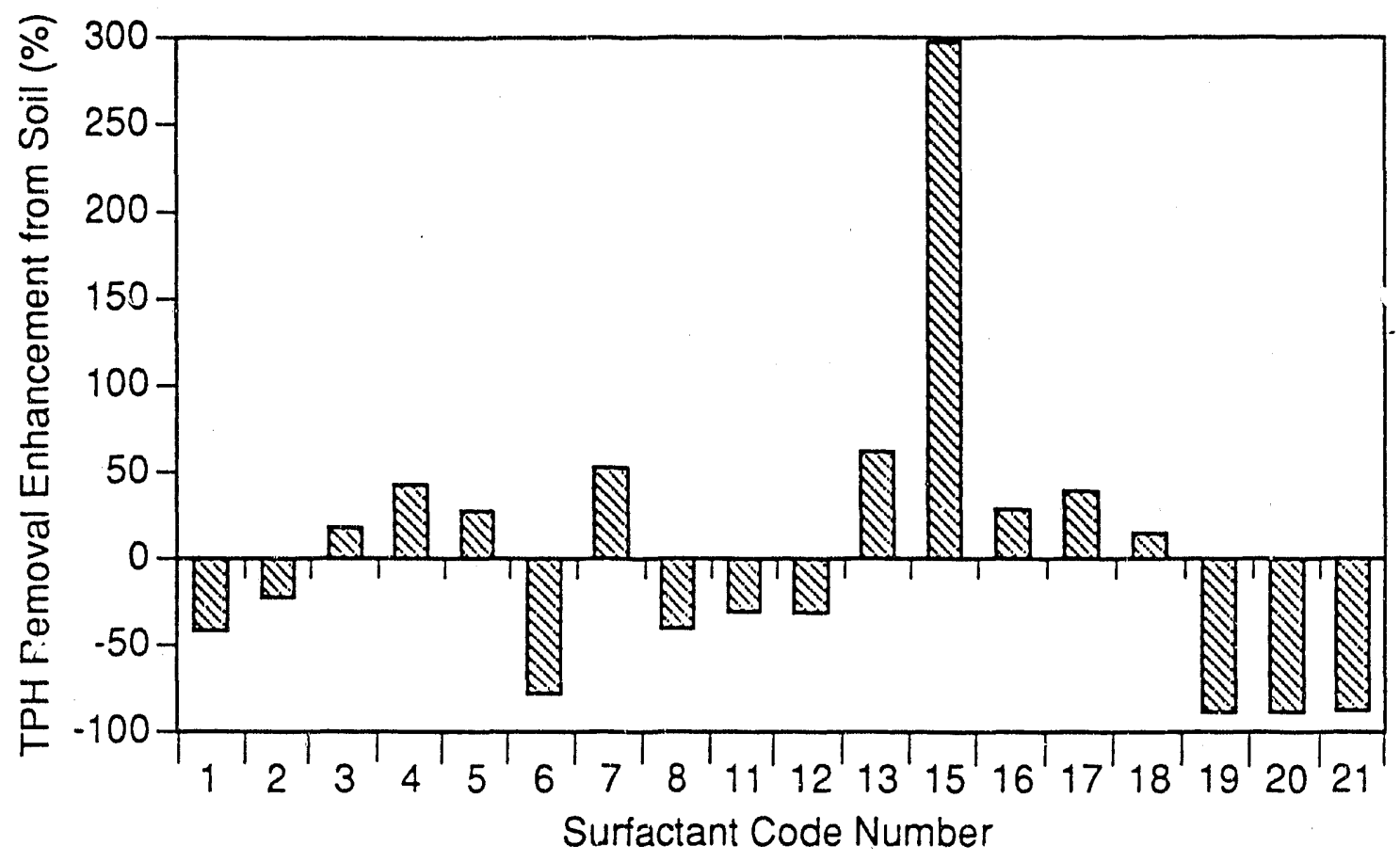

Figure 9. PERCENT ENHANCEMENT OF TPH REMOVAL EROM SOIL USING SURFACTANTS OVER WATER ALONE

in the Methods section. The peaks on the chromatograms corresponded well with the peaks (and their associated retention times) using alkane calibration standards. The results from these analyses are shown in Figures 10 through 16.

Figure 10 shows the residual alkane concentrations (in the range of $\mathrm{Cl} 2$ to $\mathrm{Cl9}$ ) on the soil using surfactants No. 13 through 18, and Figure 11 shows a cross-plot of the above data, presenting the residual alkane concentration versus the carbon number for each of the surfactants. Figure 12 shows the alkane concentration in the filtrate for surfactants No. 13 through 18 (for the range of C12 to (19). Figure 13 again represents a cross-plot of Figure 12 , showing the residual alkane concentration versus the carbon number for each surfactant. Figure 14 shows the comparison (made on the basis of $\mathrm{mg} / \mathrm{kg}$ of soill of the residual alkane concentration in both the filtrate and remaining on the soil using surfactants Nos. 13 through 18 .

All of the soils treated with these surfactants (Nos. 5 and 13 through 18) resulted in total alkane concentrations remaining on the soil being less than that using water alone. These figures indicate that surfactants Nos. 13,15, and 18 resulted in the lowest residual alkane concentrations $(<30 \mathrm{mg} / \mathrm{kg})$ remaining on the soil, whereas surfactants Nos. 16 and 17 had relatively high alkane concentrations (> $250 \mathrm{mg} / \mathrm{kg})$. Surfactants Nos. 13 and 14 had the highest alkane concentration in the filtrate (:) $560 \mathrm{mg} / \mathrm{kg}$ ). They likewise had the highest concentrations for the Cl4 to C16 range. surfactant No. 15 provided moderate alkane concentrations in the 
filtrate ( $>70 \mathrm{mg} / \mathrm{kg}$ ) and low residual alkane concentration on the soil (< $100 \mathrm{~km} / \mathrm{kg})$. Surfactant No. 13 resulted in the highest filtrate concentration ( $>620 \mathrm{mg} / \mathrm{kg}$ ) and the lowest alkane concentration remaining on the soil (<30 mg/kg). Surfactant No. 18 is somewhat of an anomaly in that it resulted in moderate alkane concentration remaining on the soil (< $140 \mathrm{mg} / \mathrm{kg})$ but had minimal alkane concentration in the filtrate. The highest alkane concentrations remaining on the soil are in the C13 to C16 range (> $30 \mathrm{mg} / \mathrm{L}$ each for surfactants Nos. 14, 16, and 17). Generally, surfactants Nos. 13, 15, and 18 had individual alkane concentrations of less than $30 \mathrm{mg} / \mathrm{kg}$.

The ranking of the total alkanes remaining on the soil was in the order for the following surfactant Nos.: $13<15<5<18<14$ $<17<16$, while the ranking of alkanes for the filtrate was in the order of $13>14>17>15>16>18 \sim 5$.

Figure 15 presents the percentage removal of the selected alkanes (C12 to C19) using surfactant Nos. 13 through 18, while Figure 16 presents the percentage removal of each alkane using the variolis surfactants. These figures indicate that the percent removal of alkanes typically exceeded $80 \%$ using surfactants Nos. 13, 15, and 18. These particular surfactants were the most effective for removal of all the alkanes in the Cl2 to C19 range. Surfactants Nos. 15 and 18 were less effective for removal of C12. of these promising surfactants (Nos. 13, 15, and 18), renovals approaching $90 \%$ are possible. Surfactants Nos. 15 and 18 are anionic surfactants, and surfactant No. 13 is a nonionic surfactant.

\section{SUMMARY AND CONCLUSIONS}

Twenty-one surfactants were screened for their effectiveness in mobilizing diesel fuel components from a contaminated soil. Overall removal of TPH generaliy exceeded $60 \%$ for those surfactants showing an enhancement in TPH removal over that of water alone. Generaliy, the anionic surfactants performed best in removing the diesel components from the soil. Surfactant Nos. 13, 15, and 18 appear to be the most promising surfactants for mobilizing the organic contaminants from this soil. These surfactants resulted in higher filtrate concentrations and relatively low residual concentrations remaining on the soil. Removals of the C12 to Cl9 alkanes by surfactants Nos. 13, 15, and 18 approached 80 to $90 \%$. These surfactants are planned for use in the surfactant flooding experiments to follow in the next phase of the project. 


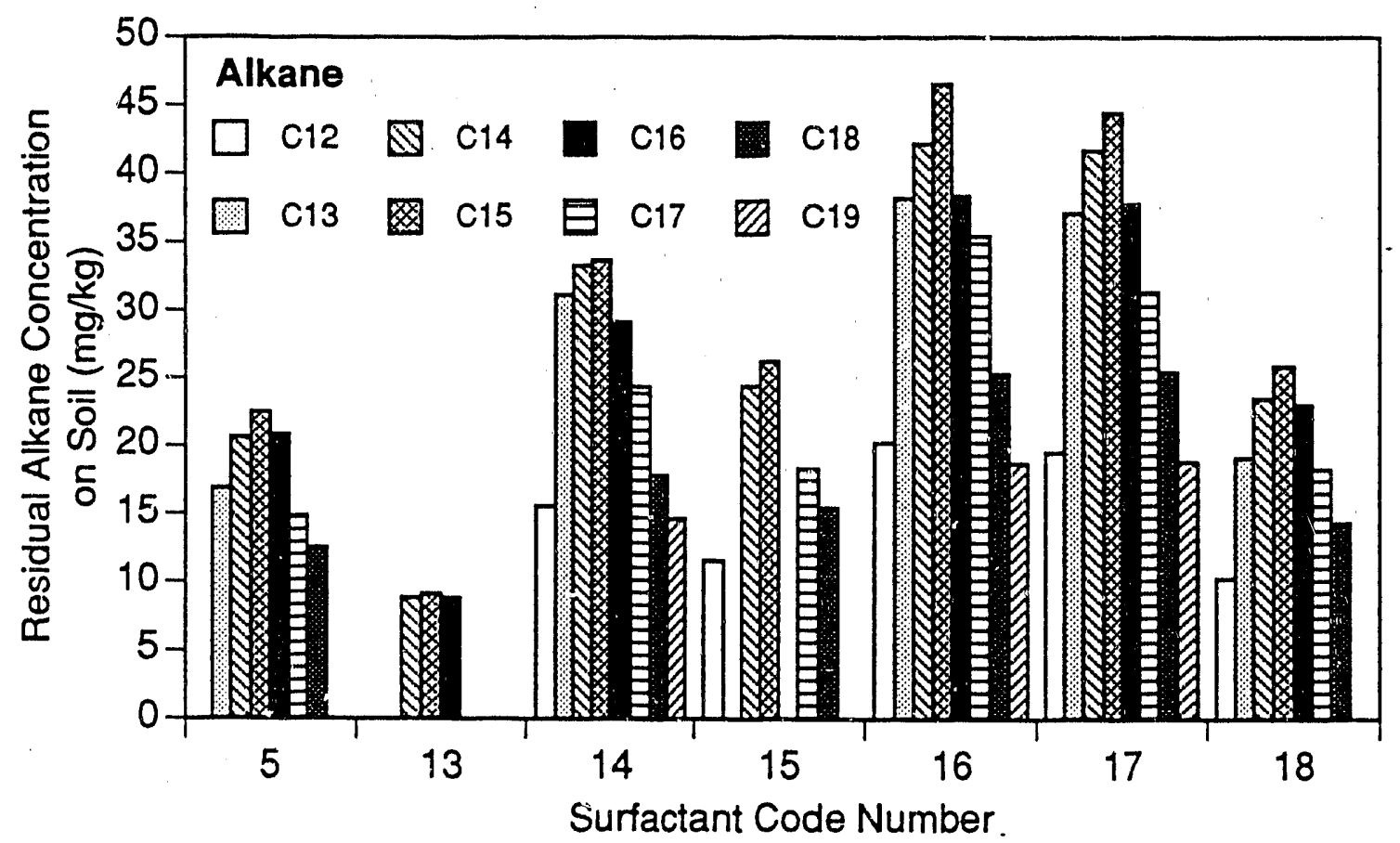

Figure 10. RESIDUAL ALKANE CONCENTRATIONS REMAINING ON SOIL FOR VARIOUS SURFACTANTS AFTER SURFACTANT TREATMENT

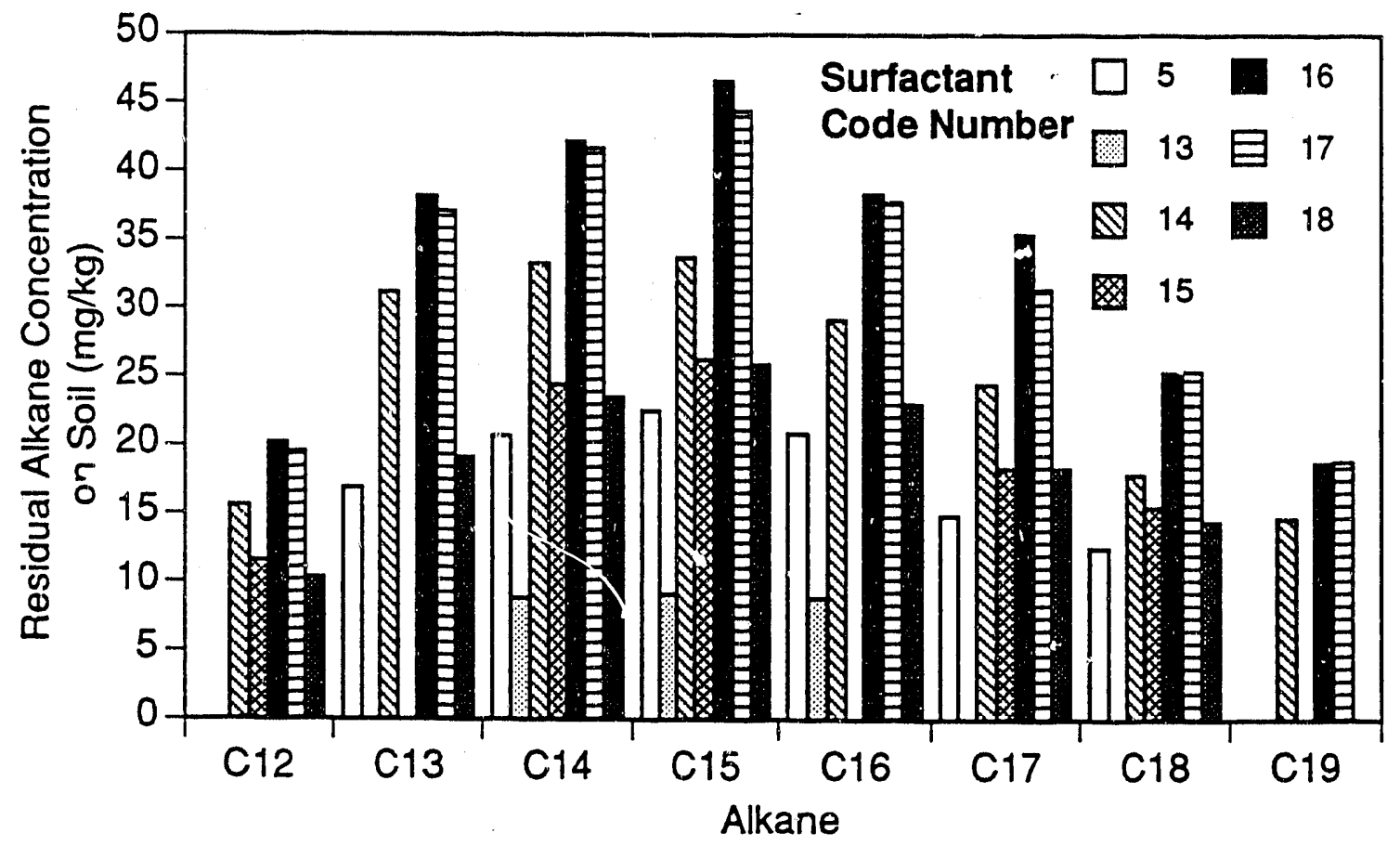

Figure 1. RESIDUAL ALKANE CONCENTRATION REMAINING ON SOIL VERSUS CARBON NUMBER AFTER SURFACTANT TREATMENT 


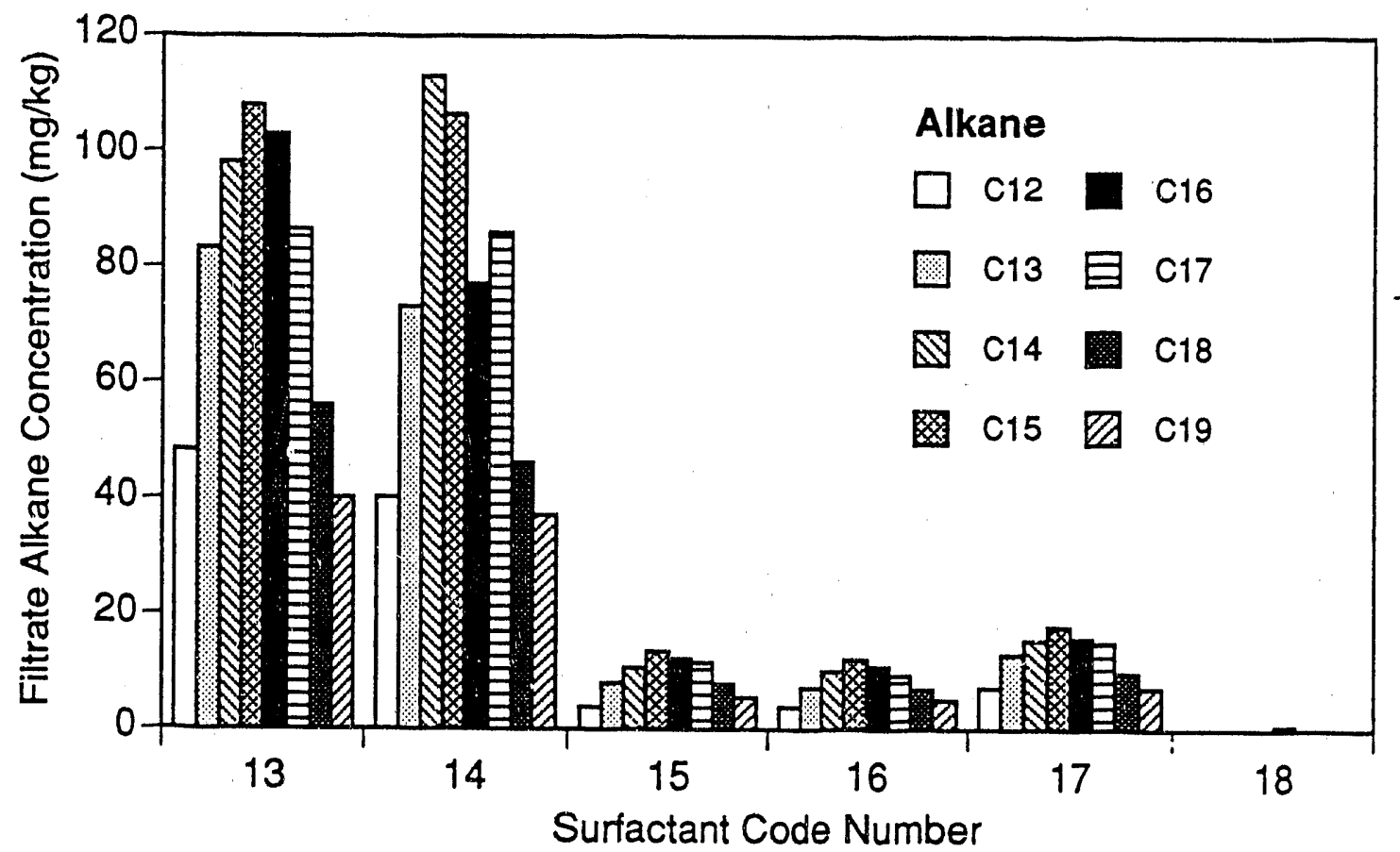

Eigure 12. MOBILIZATION OF SELECTED ALKANES (C12 TO C19) USING VARIOUS SUREACTANTS

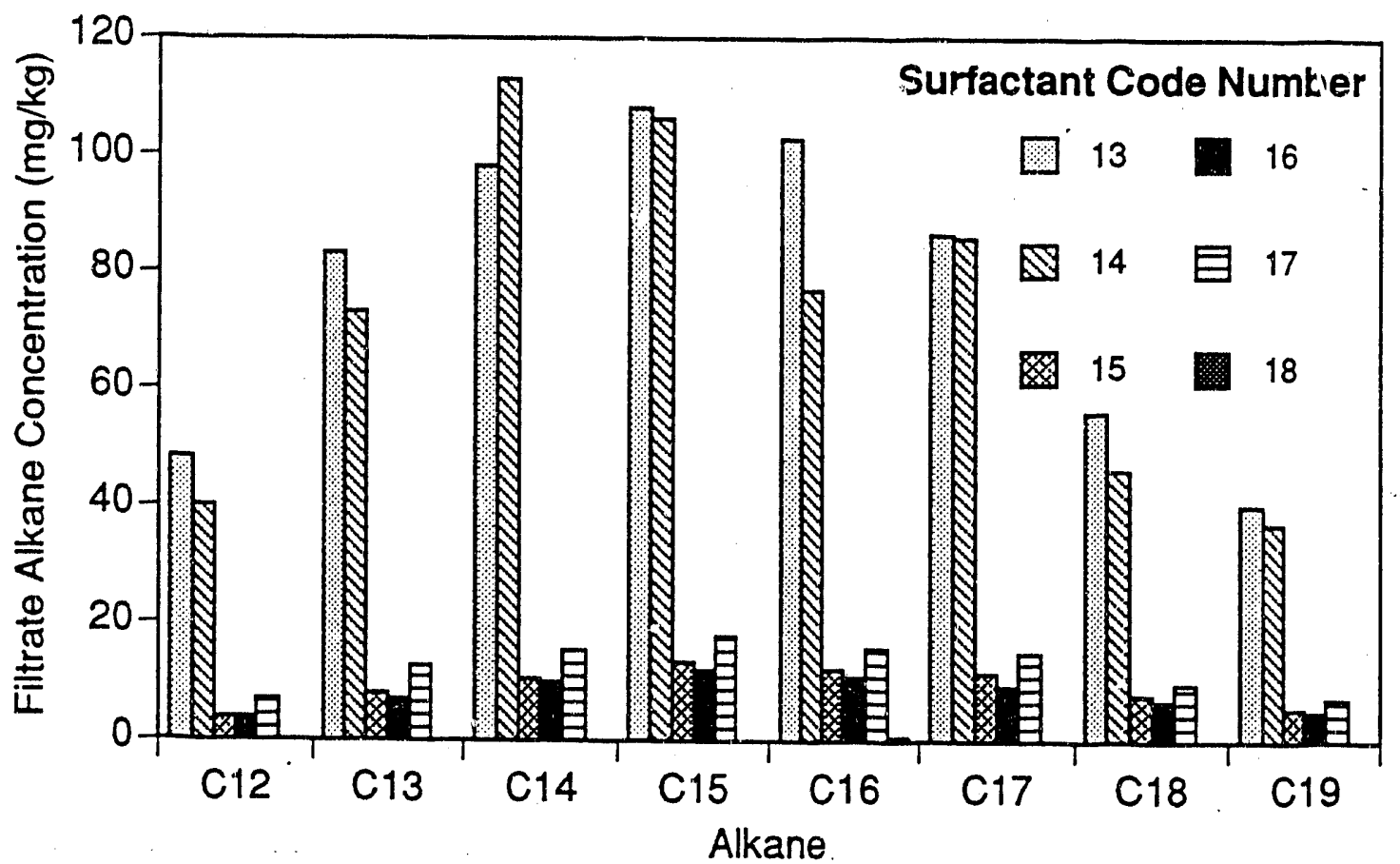

Figure 13. MOBILIZATION OF SELECTED ALKANES INTO THE SURE.ICTANT EILTRATE VERSUS CARBON NUMBER 


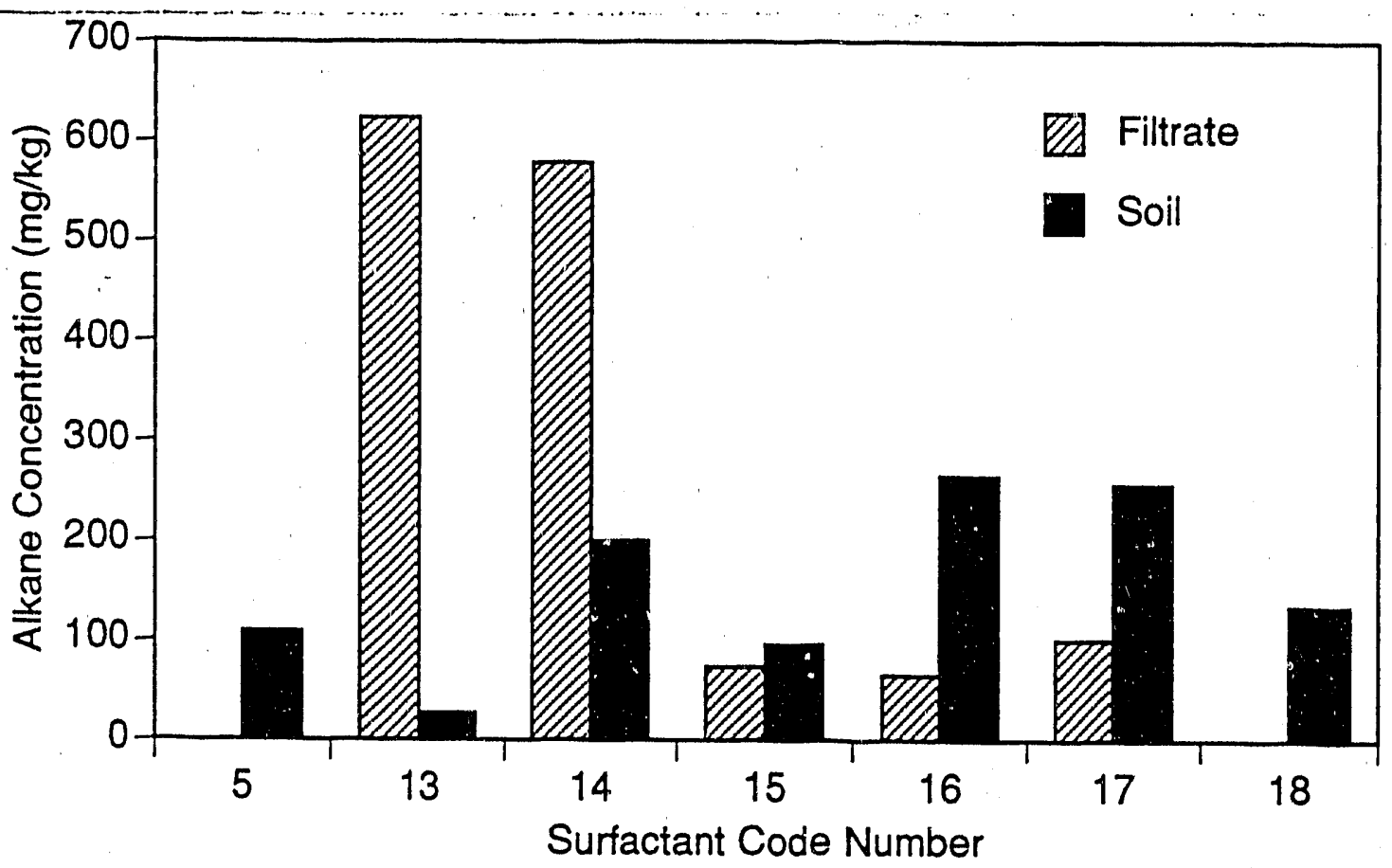

Figure 14. COMPARISON OF TOTAL ALKANE CONCENTRATION IN BOTH THE FILTRATE AND REMAINING ON SOIL AFTER SURIACTANT TREATMENT

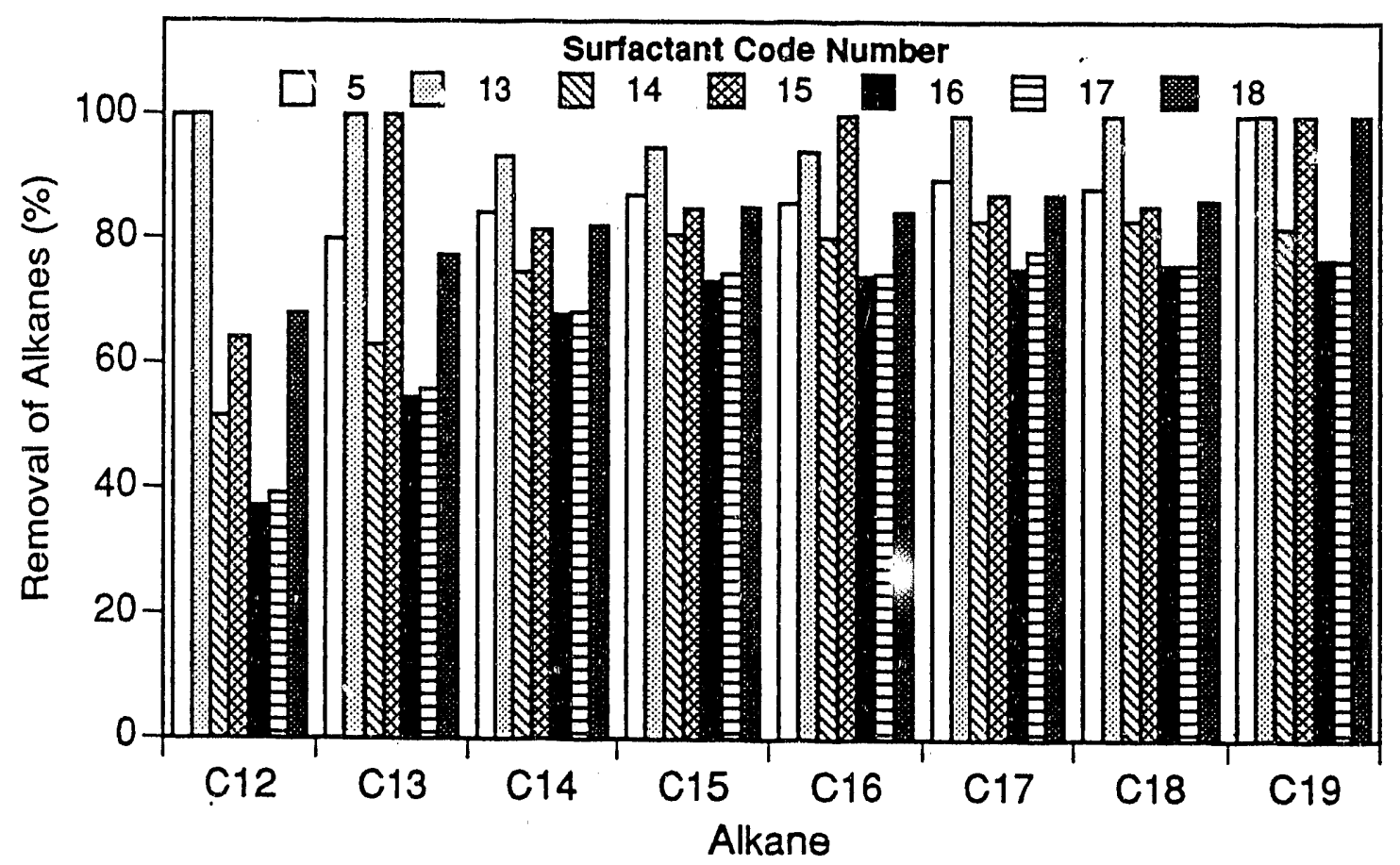

Figure 15. REMOVAL OF SELECTED ALKANES (C12 TO C19) FROM SOIL USING VARIOUS SURFACTANTS 


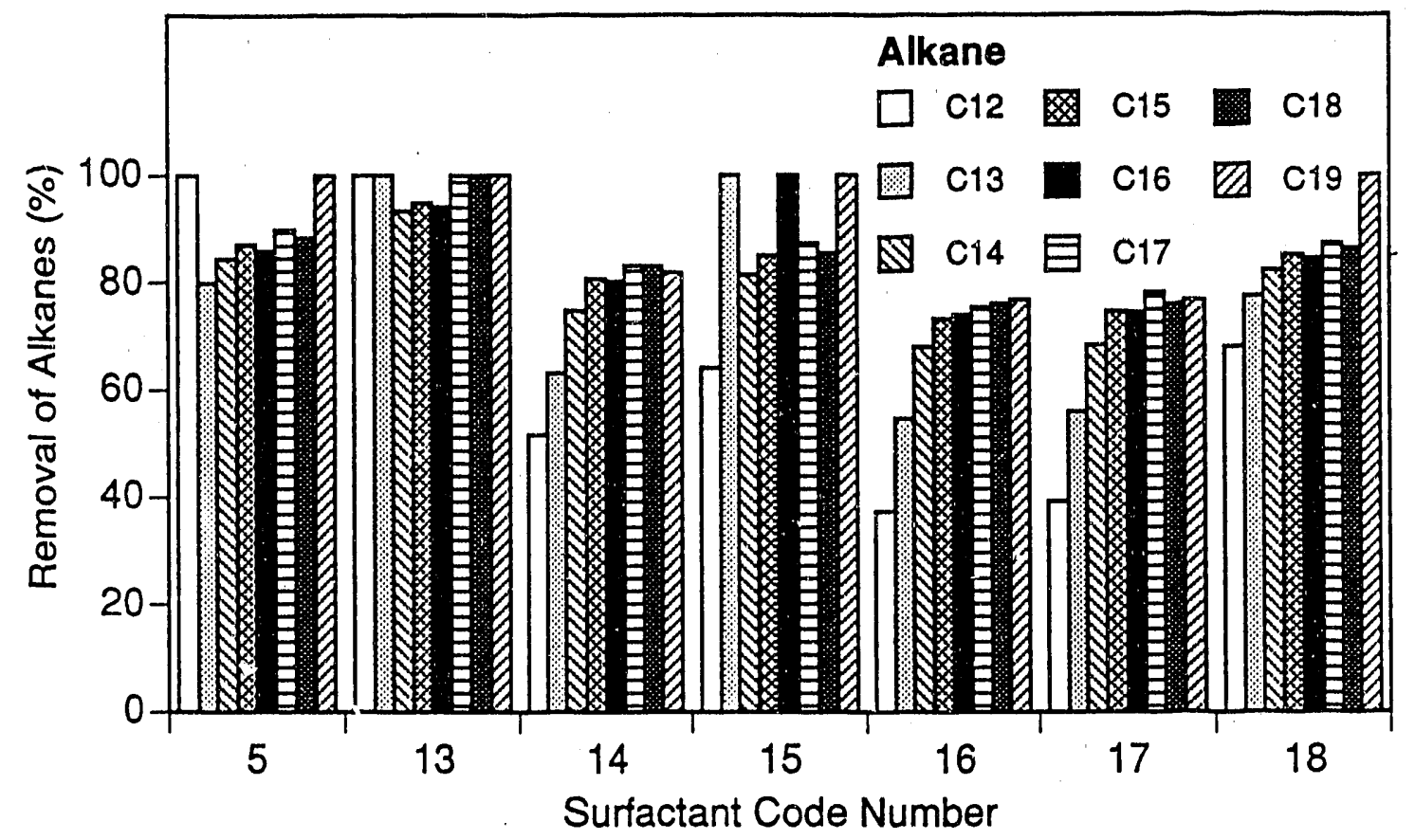

Figure 16. REMOVAL OF SELECTED ALKANES FROM SOIL VERSUS CARBON NUMBER USING VARIOUS SUREACTANTS

\section{ACKNOWLEDGMENTS}

Work supported by the U.S. Department of Energy, Albuquerque Operations office, under contracts W-7405--Eng-36 and W-31-109-Eng38. This paper was presented at the Third International IGT (Institute of Gas Technology) Symposium on Gas, Oil, Coal, and Environmental Biotechnology, held in New Orleans, Louisiana, on December 3-5, 1990. 


\section{REFERENCES CITED}

[1] Abe, S., and Seno, M., "Biodegradation of Sodium Linear Alkylbenzene-Sulfonates Evaluated with a soil Perfusion Metiod," J. Amer. Oil Chem. Soc. 64(1), 148-152 (1987).

[2] Allen, H.L., Mandel, R.M., and Evangelista, R.A., "In-Situ Treatment of Contaminated Soil by Evaporation, Soil Washing, and Biodegradation, Wells Nevada," Hazardous Material-Spilis Conference, Am. Inst. Chem. Enars. and Nat. Response Team, pp. 598-607, Chicago; IL (May 16-19, 1988).

[3] American National Standards, "Standard Method for Boiling Range Distribution of Petroleum Fractions by Gas Chromatography," ASTIM D2887-89, 492-499 (1989) Dec.

[4] Anderson, J.W., McQuerry, P.L., and Kiesser, S.L., "Laboratory Evaluation of Chemical Dispersants for Use on Oil Spills at Sea," Env. Sci. Tech. 19(5), 454-457 (1985).

[5] Donaldson, E.C., Chilingarian, G.V., and Yen, T.F., eds., Developments in Petroleum Science 17B, Enhanced Oil Reccvery. II: Processes and Operations, New York: Elsevier Science Publishing Co., 1989 .

[6] Dukes, E.P. Henson, E.P., Hutto, N., Klingsbery, A., and Maxwell, J., assoc. eds., "Surfactants," Kirk-OthmerEncyclopedia of Chemical Technology, 2nd Ed., 19, 507-593. New York: John Wiley \& Sons, Inc., 1968.

[7] Hillel, D., Fundamentals of Soil Physics, San Diego: Academic Press, 1980 .

[8] Mangano, J.J., District Sales Manager, American Cyanamid Company, Chicago, IL, private communication, (1990) sept.

[9] McGill, W.B., "Soil Restoration Following Oil spills - A Review, "J. Can. Petrol., 60-67, (1977) April/June.

[10] Nash, J.H., Field Studies of In-Situ Soil Washing, EPA 600/2$87 / 110(1987)$.

[11] National Research Council, Usina Oil Spill Dispersants on the Sea, "Chapter 2: Chemistry and Physics of Dispersants and Dispersed Oil," Washington, D.C.: Nationall Academic Press, 1989.

[12] Naylor, C.G., Castaldi, F.J., and Hayes, B.J., "Biodeýradation of Nonionic Surfactants Containing Propylene Oxide," J. Am. Oil Chem. Soc., 65(10), 1669-1676 (1988) Oct.

[13] Oh, S.G., and Slattery, J.C., "Interfacial Tension Required for Significant Displacement of Residual Oil," Soc. Petrol. Eng. J. of Am. Inst. Mech. Engrs., 19(1), 83-90 (1979) April. 
[14] Rickabaugh, J., Clement, S., and Lewis, R.F., "Surfactant Scrubbing of Hazardous Chemicals from Soil," $\underline{P}$ OC. 41st Purdue Indus. Waste Conf., 41, 377-382 (1986).

[15] State of California, Leakina Underground Fuel Tank Field Manual: Guidelines for Site Assessment, cleanup and Underground Storage Tank Closure, Leaking Underground Fuel Tank Task Force (1989) Oct.

[16] Tyler, S.W., Whitebeck, M.R., Kirk, M.W., and Hes., J.W., Processes Affecting subsurface Transport of Leaking Underground Tank Fluids, U.S. Environmental Protection Agency (1987).

[17] Valine, S.B., Chilcote, D.D., and Zambrano, A.R., "Development of Soil Washing System," Proc. 44th Purdue Indus. Waste Conf. , 44, 83-89 (1989).

[18] Wilson, J.T., Evaluation of Soils for In-Situ Treatment, U.S. Environmental Protection Agency, EPA/600/2-39/042 (1989) july. 


\section{APPENDIX I}

\section{Sample Calculations:}

\section{Calculation for TPH}

a. Varian Gas Chromatograph

From created external standard calibration curve:

$$
\begin{aligned}
& y=m * x+b \\
& \text { where: } \begin{aligned}
y & =\mu g \text { TPH injected } \\
x & =\text { area counts of } G C \\
m & =\text { slope } \\
b & =y \text {-intercept }
\end{aligned}
\end{aligned}
$$

b. Hewlett-Packard Gas Chromatograph

From known external standard calibration:

$$
\begin{aligned}
& y=(x / c) \star \mu g / 1000 n g \\
& \text { where: } c=\text { area counts per ng of standard }
\end{aligned}
$$

C. Conversion to TPH in $\mathrm{mg} / \mathrm{kg}$.

$$
\begin{aligned}
& \mathrm{mg} \mathrm{TPH} / \mathrm{kg} \text { soil }=y / \mu \mathrm{g} \mathrm{CS}_{2} \text { inj } \text { * } \\
& \text { ( } \mu \mathrm{g} \mathrm{CS}_{2} \text { total/mg slurry mixed) * }
\end{aligned}
$$$$
\text { (mg slurry total/gm soil) * }
$$$$
1000 \mathrm{gm} / \mathrm{kg} \text { * } 1 \mathrm{mg} / 1000 \mu \mathrm{g}
$$

II. Mass Balance Calculation

Total Initial $\mathrm{TPH}(\mathrm{mg})=\mathrm{TPH}$ of treated soil (mg) + TPH of slurry filtrate (mg) TPH of surfactant control (mg.) 


\section{APPENDIX II}

\section{Gas Chromatography Analyses}

The operation of the gas chromatographs (Varian and HewlettPackard) are described in the Methods section of this paper. - The standards for these two GCs are described below.

\section{Standards for the Varian Gas Chromatograph}

External standards were used to calibrate the instruments. As prescribed in the California LUFT manual [15], a commercial grade of No. 2 diesel fuel obtained from a local service station was chosen as the standard. A concentration of $6 \mu \mathrm{L}$ diesel fuel to 5 $\mathrm{mL} \mathrm{CS} \mathrm{CS}_{2}$ was used. This concentration was chosen because $6 \mu \mathrm{L}$ of diesel fuel corresponds to approximately $5 \mu \mathrm{g}$ and the ratio of $\mathrm{mg}$ diesel fuel to $\mathrm{mL} \mathrm{CS} \mathrm{CS}_{2}$ is $1: 1(\mu \mathrm{g} / \mu \mathrm{L})$. This allows easy calculation comparing ug dissel injected to $\mu \mathrm{L} \mathrm{CS}_{2}$ solution injected.

To form a standard curve, the standard diesel solution was injected at various amounts from $1 \mu \mathrm{L}$ to $10 \mu \mathrm{L}$, performed 2 to 3 times each. Averages of total area counts for each amount were plotted versus the injection amounts. The amount injected in $\mu L$ correspcnded to the amount of diesel injected in $\mu \mathrm{g}$. A linear regression was used to produce a standard curve and a range was given to the average points on the curve from the area values of the actual injections as opposed to calculating a standard errur (because few points were used). The concentration of each sample was determined by plotting total area counts of the standard curve to estimate the $\mu \mathrm{g}$ in the injection. Daily standards were run as a constant monitoring of the column's performance. Because of column drift (determined when the daily standard deviated from the initial standard curve), the column had to be replaced on several occasions. Several fresh standards (standards Nos. 1 through 7) were prepared to make sure the deviation from the standard curve was not due to evaporation of the standard bixt rather due to drifting of the column.

\section{Precision and Accuracy of the Varian Gas Chromatograph}

To check the accuracy of the GC, several standards of various concentratinns were prepared $(2.03,2.54,3.0,3.55$, and $4.06 \mu \mathrm{g} / 3-$ $\left.\mathrm{mL} \quad \mathrm{CS}_{2}\right)$. Results of this test are presented in Table 2. An accuracy test using results from a GC run to determine a spike doubling the concentration is pending. This second methud was used to determine the accuracy of the Hewlett-Packard GC and is described below. Precision of the instrument was determined by performing at least two runs of each sample. If the difference between total area counts of these two runs was greater than $20 \%$, a third run was also performed. Precision was also confirmed by daily standard runs (see Table 3 ). 
Table 2. VERIFICATION OF ACCURACY OF VARIAN GAS CHROMATOGRAPH

\begin{tabular}{lcrrrr}
\hline $\begin{array}{c}\text { Standard } \\
\text { No. }\end{array}$ & $\begin{array}{c}\text { Diesel Concen- } \\
\text { tration, } \\
(\mu\llcorner/ 3 \mathrm{ml} \mathrm{CS})\end{array}$ & Area & $\begin{array}{c}\text { Injection } \\
\text { into GC, } \\
(\mu \mathrm{g})\end{array}$ & $\begin{array}{c}\text { Diesel Mass } \\
\text { vieasured, } \\
(\mu \mathrm{g})\end{array}$ & $\%$ Error \\
\hline & & & & & \\
1 & 2.4 & 714528 & 3.42 & 2.02 & 36.0 \\
2 & 3.0 & 972007 & 4.27 & 2.80 & 34.0 \\
3 & 3.0 & 911133 & 4.27 & 2.99 & 30.0 \\
4 & 3.0 & 1015859 & 4.27 & 3.12 & 26.0 \\
5 & 3.6 & 1577411 & 5.13 & 4.83 & 5.7 \\
6 & 4.2 & 1259965 & 5.98 & 3.87 & 35.4 \\
7 & 4.8 & 1722523 & 6.83 & 5.28 & 22.8 \\
\hline
\end{tabular}

Table 3. DAILY STANDARD

RUNS ON VARIAN GAS

CHROMATOGRAPH

\begin{tabular}{llc}
\hline & & \\
\cline { 3 - 3 } Date & Area & $\%$ Error \\
& & \\
\hline $7 / 03$ & 1192900 & 3.5 \\
$7 / 04$ & 1325700 & 15.0 \\
$7 / 09$ & 935430 & 18.9 \\
$7 / 10$ & 1016200 & 11.9 \\
$7 / 11$ & 1190500 & 3.3 \\
$7 / 13$ & 1325600 & 15.0 \\
$7 / 14$ & 1185700 & 9.3 \\
$7 / 15$ & 1267900 & 3.0 \\
$7 / 16$ & 1241700 & 7.7 \\
$7 / 17$ & 1446200 & 25.4 \\
& & \\
\hline
\end{tabular}

Standard of the Hewlett-Packard (HP) Gas Chromatograph

The same standards that were prepared for the Varian GC were used for the HP GC. However, instead of creating a calibration curve (as described for the Varian GC), the calibration was performed by injecting constant amounts $(2.0 \mu \mathrm{L})$ of various concentratiors of the standards prepared. The HP gas chromatograph was unable to handle amount:s larger than $3.0 \mu \mathrm{L}$ due to its sensitivity, Using total area counts and knowing the amount of diesel injected, an average counts/amount (cts/ng) of diesel fuel was calculated. This value was then used for sample runs to determine concentrations of TPH in each sample (see Appendix I for sample calculations). 


\section{Precision and Accuracy of Hewlett-Packard Gas Chromatograph}

To check the precision of the HP GC, several runs of the standard No. 7 were performed. The average and standard deviation were calculated and are presented in Table 4. Accuracy was tested by determining the TPH of a sample with the HP GC, then spiking the sample with diesel fuel to double the amount in the sample. This spiked sample was also analyzed using the GC. If the total area of the spiked sample was twice that of the unspiked sample, then the results proved accurate (see Table 5).

Select samples were analyzed on both gas chromatographs to compare performances of these two GCs.

\section{Mass Balances}

Mass balances on the diesel fuel for each surfactant treatment were calculated with the results of gas chromatography determinations (see Appendix I for calculations). It was assumed that detection of the sample diesel and surfactants by the flame ionization detector was similar to that of standard diesel. This involves the assumption that the counts/ng would be representative of the samples as well as for the standard diesel. This value, however, is most likely not representative of the surfactant amounts detected. In the mass balances, the presence of the surfactant components detected were accounted for by subtracting the amount determined in the surfactant control from the added amounts of compounds detected in both the filtrate and the rreated soil.

However, amounts of TPH given in mg/kg of soil in the results include the surfactant components associated with the particular sample. To limit erroneously high results, total areas of the chromatograms were taken up to the retention time of the last diesel peak expected. This eliminated some, but not all,

Table 4. VERIFICATION OF PRECISION OF HEWLETT-

PACKARD GAS CHROMATOGRAPH

\begin{tabular}{cccccc}
\hline $\begin{array}{c}\text { Standard } \\
\text { No. }\end{array}$ & $\begin{array}{c}\text { Mass of } \\
\text { Diesel, }\end{array}$ & $\begin{array}{c}\text { Total } \\
\text { Area* } \\
(\mu \mathrm{g})\end{array}$ & Date & Area & $\%$ Error \\
\hline & & & & & \\
\hline 1 & 3.0 & 12392.2 & $9 / 26$ & 11831.0 & 3.80 \\
2 & 3.0 & 12270.2 & $10 / 1$ & 12228.0 & 0.60 \\
3 & 3.0 & 12702.6 & $10 / 5$ & 12290.0 & 0.07 \\
4 & 3.0 & 11831.0 & $10 / 9$ & 12924.5 & 5.10 \\
\hline
\end{tabular}

- Mean Area $=12299.0 ;$ Standard Deviation $=361.2$ 
Table 5. VERIFICATION OF THE ACCURACY OF THE HEWLETTPACKARD GAS CHROMATOGRAPH

\begin{tabular}{|c|c|c|c|c|c|c|}
\hline \multirow{2}{*}{$\begin{array}{l}\text { Carbon } \\
\text { Number }\end{array}$} & \multicolumn{5}{|c|}{$\begin{array}{l}\text { Area Measurement } \\
\text { Trial No. }\end{array}$} & \multirow{2}{*}{$\begin{array}{c}\text { Area } \\
\text { (with } \\
\text { Spike)* }\end{array}$} \\
\hline & 1 & 2 & 3 & 4 & Mean & \\
\hline $\mathrm{C}_{12}$ & 30.2 & 30.0 & 32.3 & 36.3 & 32.2 & 86.7 \\
\hline $\mathrm{C}_{13}$ & 80.3 & 78.9 & 87.1 & 90.4 & 84.2 & 174.7 \\
\hline$C: 4$ & 428.5 & 117.2 & 137.9 & 142.6 & 131.6 & 204.2 \\
\hline C15 & 165.5 & 156.9 & 191.4 & 182.1 & 174.0 & 290.1 \\
\hline$C_{16}$ & 1.42 .4 & 130.9 & 145.0 & 171.5 & 147.5 & 264.9 \\
\hline$C_{17}$ & 146.9 & 129.3 & 145.0 & 152.3 & 143.4 & 242.4 \\
\hline C18 & 105.8 & 89.8 & 109.4 & 117.1 & 105.5 & 153.7 \\
\hline C19 & 79.1 & 73.0 & 75.2 & 95.9 & 80.8 & 95.1 \\
\hline Total & 878.7 & 806.0 & 923.3 & 988.2 & 899.2 & 1511.8 \\
\hline
\end{tabular}

- Spike is a doubling of the concentration.

interference due to the surfactant components. The best determination of the effectiveness of the surfactant to mobilize the diesel components was to look at the chromatograms themselves (and the individual peaks characteristic of diesel) to determine the fraction of diesel liberated into solution and the fraction remaining on the soil. A mathematical analysis of the individual peaks was not considered for two reasons. First, the number of peaks involved in diesel fuel is numerous, and it would be very difficult to determine which compound each peak corresponded to; and second, the purpose of the screening process was to obtain a quick assessment of the effect of the surfactants for mobilizing the diesel comporents. To examine all. the peaks involved would be too time consuming and would not necessarily enhance the screening process evaluation. 

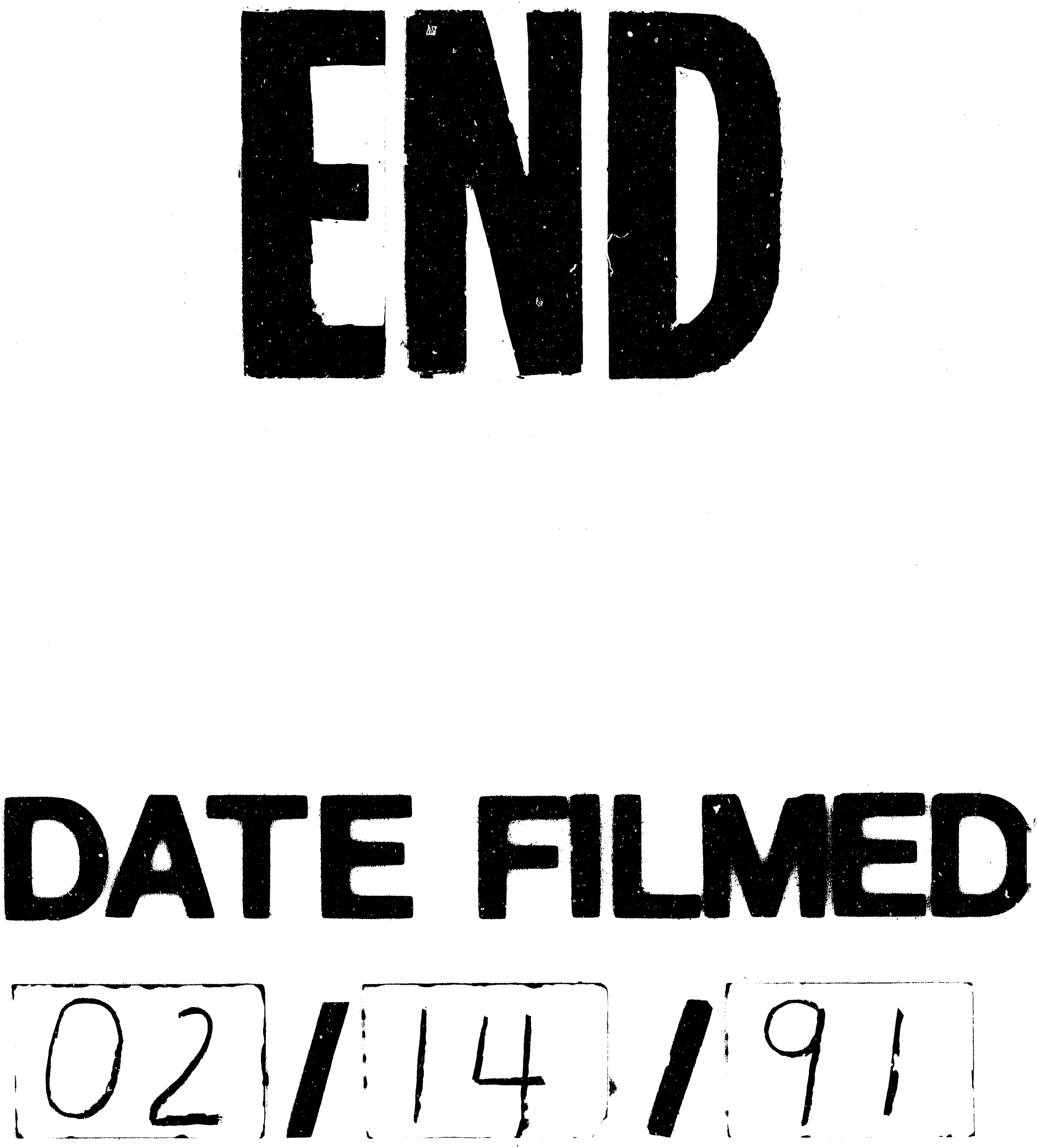
